\title{
LA EFICACIA HORIZONTAL DE LOS DERECHOS FUNDAMENTALES
}

\section{HORIZONTAL EFFECT OF CONSTITUTIONAL RIGHTS}

\author{
José Juan ANZURES GURRÍA
}

RESUMEN: Si se entiende que los derechos fundamentales son límites al poder, y hoy en día el poder (económico o social) se ostenta no sólo por el Estado sino también por los particulares, resulta razonable expandir la eficacia de estos derechos a las relaciones privadas, según predica la teoría de la Drittwirkung. La cual se divide en dos corrientes, la mediata y la inmediata; la primera sostiene que la forma en que los derechos fundamentales despliegan sus efectos en las relaciones privadas será mediante la intervención de un órgano del Estado, concibiendo a los derechos como valores objetivos; la segunda, entiende que los derechos fundamentales son verdaderos derechos subjetivos y por ello no hace falta la intervención de ningún órgano estatal. Pero más que teórico, el problema es procesal y radica en hallar la protección jurisdiccional de los derechos fundamentales, ante su posible vulneración, en las relaciones particulares; problema que el Tribunal Constitucional español ha resuelto imputando la violación de los derechos fundamentales que tuvo origen en una relación privada, al Poder Judicial, pues éste tiene por mandato constitucional el deber de protegerlos.

Palabras clave: Drittwirkung, eficacia horizontal mediata, eficacia horizontal inmediata, valores objetivos, derechos subjetivos, asunción judicial.
ABSTRACT: If constitutional rights are conceived as limits to the power, and nowadays the power (economic or social) belongs not only to the State, but also to private persons, is reasonable to expand the effects of these rights to private relations, according to the Drittwirkung theory. This theory has two trends, the indirect and the direct one. The first one maintains that, the way that constitutional rights displayed their effects in private relations is through a State body, and conceives these rights as objective values; the second one, understands that, these rights are subjective rights, and for that reason is not necessary a State body. But the main problem of this theory lies in finding the way to protect these rights, against their violation, in private relations. This problem has been solved by the Constitutional Court of Spain attributing the violation of constitutional rights in a specific private relation, to the Judicial branch, because it has a constitutional commandment to protect them.

Descriptors: Drittwirkung, Indirect Horizontal Effect, Direct Horizontal Effect, Objective Values, Subjective Rights, Judicial Imputation. 


\section{INTRODUCCIÓN}

Los derechos fundamentales contenidos en las nuevas constituciones normativas de los Estados sociales y de derecho que nacen después de la Segunda Guerra Mundial, serán concebidos ya no sólo como límites o prerrogativas frente al poder público sino también frente a los particulares. Es decir, desplegarán su eficacia frente a terceros o también llamada eficacia horizontal.

Si en un principio, los derechos fundamentales y las libertades públicas consagrados en la Ley Fundamental de Bonn siguieron siendo concebidos como límites y garantías de los ciudadanos frente a las injerencias del poder del Estado, desde muy temprano, la doctrina y los tribunales alemanes reconocerán que estos derechos también despliegan sus efectos en las relaciones privadas, pues los códigos decimonónicos, —que respondían a las necesidades políticas imperantes en los Estados liberales del siglo XIX - ya no sirven para dar respuesta a las exigencias de dignidad, libertad e igualdad que tras la Segunda Guerra Mundial forman parte del estatus de toda persona de un modo multidereccional o pluridimencional.

La trascendencia y quizá la razón principal por la que esta teoría ha sido objeto de tanta atención radica precisamente en que viene a cuestionar la concepción clásica de los derechos fundamentales como límites al poder del Estado.

En términos generales, no obstante, parece haber cierto consenso en que los derechos fundamentales despliegan sus efectos en el tráfico jurídico privado. El objeto de la discusión que ha mantenido ocupada a la doctrina constitucional durante los últimos 60 años se ha centrado más bien en determinar la forma y modo en que estos derechos han de hacerse efectivos en las relaciones privadas.

Pero más que teórico, el problema parece ser procesal, pues como pretende analizarse en este trabajo (sin dejar a un lado la discusión doctrinal), la dificultad radica en dotar a los derechos fundamentales de una garantía jurisdiccional que les dispense de la debida protección en el tráfico jurídico privado, o bien, que remedie la agresión del derecho fundamental una vez afectado, tal y como opera el recurso de amparo frente a las actuaciones del poder público. Pero no siendo esto posible, por razones que se explicarán más adelante, la solución parece encontrarse en la teoría de la asunción judicial y en el reconocimiento del importante 
papel que desempaña la jurisdicción ordinaria como garante de los derechos fundamentales en un Estado social y democrático de derecho.

\section{JUSTIFICACIÓN DE LA EFICACIA HORIZONTAL DE LOS DERECHOS FUNDAMENTALES}

\section{El argumento histórico}

Existe todavía algún sector académico que, principalmente desde la trinchera del derecho privado, se esfuerza en negar la eficacia horizontal de los derechos fundamentales acudiendo a su origen histórico; arguyendo que si éstos nacieron como límites al poder del Estado, concebirlos como vinculantes en las relaciones particulares es desvirtuar por completo su naturaleza jurídica. ${ }^{1}$

No obstante, dos son los argumentos que pueden servir para dejar a un lado esta postura clásica. El primero de ellos sostiene que la función con la que surgieron los derechos fundamentales en las declaraciones de derechos y Constituciones de finales del siglo XVIII obedeció, no sólo a limitar el poder de los Estados nacientes, sino también y principalmente a regular la vida del hombre que ingresaba en el estado de sociedad; el segundo argumento arguye que la noción actual de los derechos fundamentales es producto de su evolución histórica y en consecuencia, la Drittwirkung constituye hoy en día una de sus características esenciales.

Respecto al primer punto, ha sido principalmente J. Rivero quien ha argumentado que:

1 Existen todavía algunos sectores, sobre todo en el área del derecho civil, que se niegan a aceptar la Drittwirkung, para Alfaro Águila-Real, los destinatarios de los derechos fundamentales y sus garantías son sólo los poderes públicos. "Autonomía privada y derechos fundamentales”, $A D C$, vol. 46, núm. 1, 1993, p. 60. En 1959 E. Forsthoff, escribió que: "Los derechos no constituyen un 'sistema', porque cada uno de aquellos responde en su establecimiento una finalidad protectora del ciudadano frente al poder público, ni cabe referir al Estado la función de fijación de los valores, que es un concepto filosófico cuya imputación y cuyo dominio es exclusivo de la persona individual...", más adelante señala que "nadie ha demostrado que la Drittwirkung responde a una autentica necesidad social patentizada por la conveniencia de proteger al individuo frente a grupos sociales ajenos al Estado, por ausencia de otros cauces jurídicos", Die Umbildung des Verfassungsgesetzes, Festschrift für Carl Schmitt, Duncker und Humblot, Berlín, 1959, p. 35. 
la doctrina liberal nació en realidad con una doble virtualidad: una movida por una desconfianza insuperable hacia el Estado, que lo empuja a una abstención generalizada respecto al ámbito de las relaciones privadas, y otra, que convierte al Estado democrático en el garante y regulador de esas mismas libertades.

Si bien es la primera postura la que ha prevalecido durante mucho tiempo, para este autor,

se puede afirmar, no sólo que la una es tan auténticamente liberal como la otra, sino que la segunda concepción, que ve en la regulación de las relaciones privadas por el Estado un medio necesario para garantizar el ejercicio efectivo de las libertades es, en definitiva, la más fiel al pensamiento inicial de los autores de la Declaración de $1789 .^{2}$

Los derechos recogidos en la Declaración Francesa del Hombre y del Ciudadano, así como en la de Virginia de 1776, fruto de las teorías contractualistas de la época, obedecen a la concepción de los derechos como naturales. ${ }^{3}$ Es decir, como derechos que el hombre tiene por su condición humana y que conserva a pesar de entrar en el estado de sociedad. ${ }^{4} \mathrm{Se}$ trata de derechos que en términos de I. Kant, "independientemente de un acto jurídico, son transmitidos a cada individuo por la naturaleza", 5 derechos que el hombre ostenta no sólo contra la autoridad del Estado, sino también contra los privilegios corporativos y clericales, y contra las

2 Rivero, J., "La protection des droits de 1'homme dans les rapports entre persones privées", en Varios Autores, René Cassin Amicorum Discipulorumque Liber, t. III, Protection des droits de l'homme dans les raports entre persones privées, París, Pedone, 1971, p. 316.

3 El artículo 1o. de la Declaración de Virginia señala: "que todos los hombres son por naturaleza igualmente libres e independientes y poseen ciertos derechos inherentes, de los cuales, cuando entran en un estado de sociedad, no pueden privar o desposeer a su posterioridad en virtud de pacto alguno, a saber: el goce de la vida y de la libertad, junto con los medios de adquirir la propiedad, así como la búsqueda y logro de la felicidad y la seguridad".

4 Cruz Villalón, P., "Formación y evolución de los derechos fundamentales", REDC, núm. 25, 1989, p. 45.

5 Kant, I., Metaphysiche Anfangsgründe der Rechtslehere, 1979, citado por W. Cesarini Sforza, voz "Diritto Soggettivo", Enciclopedia del Diritto, Milán, Giuffrè, 1993, p. 677. 
prerrogativas económicas y sociales del derecho privado ${ }^{6}$ y que tienen por objeto que la persona se desenvuelva de manera libre e igual en sus relaciones particulares. ${ }^{7}$ Para L. Prieto Sanchís ${ }^{8}$ y J. Ballarín Iribarren, ${ }^{9}$ estos derechos (los naturales) son siempre derechos en las relaciones entre privados, pues en el estado de naturaleza no existe poder.

Así, los derechos naturales de cada hombre son efectivos en la medida en que los demás miembros de la sociedad gozan de igual forma de éstos. El artículo 4o. de la Declaración Francesa de 1789 es muy ilustrativo en este sentido al señalar que: "la libertad consiste en hacer todo aquello que no perjudica a los demás". Así, la idea de la libertad nace como libertad personal por un lado, y como libertad del hombre en sociedad, por el otro. ${ }^{10}$

Se debe aclarar, llegados a este punto, que en ningún momento se está negando que los derechos fundamentales hayan nacido como límites al poder público, pero no creemos que ésta haya sido su única y exclusiva función, ${ }^{11}$ sino que aunado a ella, los derechos fueron concebidos también para regular las relaciones particulares, y como tales constituían un mandato de protección hacia el Estado que debía procurar su observancia y respeto por todos los ciudadanos en sus relaciones sociales. Es más, si el surgimiento del Estado se va a justificar, va a ser en la medida en que salvaguarde y haga efectivos estos derechos. ${ }^{12}$ "La finalidad máxima y

6 Julio Estrada, A., La eficacia de los derechos fundamentales entre particulares, Universidad Externado de Colombia, 2000, p. 31.

7 Así lo demuestran Leisner, W. y Bleckmann, A., Staatsreecht II- Die Grundrechte, 3a. ed., Köln, Car Heymann Verlag GmbH, 1989.

8 Prieto Sanchís, L., Estudios sobre derechos fundamentales, Madrid, Debate, 1990, pp. 206 y 207.

9 Ballarín Iribarren, J., "Derechos fundamentales y relaciones entre particulares (la "Drittwirkung" en la jurisprudencia del Tribunal Constitucional", REDC, núm. 24, septiembre-diciembre de 1988, p. 286.

10 Venegas Grau, M., Derechos fundamentales y derecho privado. Los derechos fundamentales en las relaciones entre particulares y el principio de autonomía privada, Madrid, Marcial Pons, 2004, p. 124.

11 J. Ballarín Iribarren sostiene que "no hay nada en el concepto general de los derechos fundamentales, considerando la génesis del mismo, que obligue a considerar que, en principio, se tienen sólo frente a los poderes públicos, que sólo para éstos nazcan de ellos limitaciones en su actuar", en op. cit., nota 9, p. 288.

12 Peces-Barba Martínez, G., Lecciones de derechos fundamentales, Madrid, Dykinson, 2004, p. 335. 
principal que buscan los hombres al reunirse en Estado o comunidades, sometiéndose a un gobierno, es la de salvaguardar sus bienes", dirá J. Locke. ${ }^{13}$ De tal forma que, como afirma H. G. Suelmann:

de la interpretación histórica de los derechos fundamentales en absoluto se puede concluir que, por principio, los derechos no estén en condiciones de proteger a los sujetos jurídicos-privados. Antes al contrario, esta interpretación aboga por la posibilidad de una eficacia horizontal de este tipo. ${ }^{14}$

De igual forma H. C. Nipperdey negaba que la función histórica de los derechos fundamentales como límites al poder, fuera una razón válida para negar la vinculación directa de éstos entre los particulares. ${ }^{15}$

Cosa distinta es que se hable de los derechos públicos subjetivos, ${ }^{16}$ que son derechos que ostentan los individuos en sus relaciones jurídicas con el Estado, considerado como persona jurídica. Éstos son derechos que pertenecen a los particulares en tanto son miembros del Estado, ${ }^{17} \mathrm{y}$ de hecho, si el individuo es considerado persona - sujeto de derechoslo va a ser en tanto sea miembro del Estado, pues éste es el que le atribuye la capacidad para requerir eficazmente la tutela jurídica estatal. Es el Estado el que le crea la personalidad al individuo, éste no la tiene por su condición de persona. ${ }^{18}$

13 Locke, J., Ensayo sobre el gobierno civil (segundo tratado, 1690), trad. de A. Lázaro Ros, Madrid, Aguilar, 1969, epígrafe 124.

14 Suelmann, H. G., Die Horizontalwirkung des Art. 3 II GG, Baden-Baden, Nomos Verlagsgesellschaft, 1994, p. 65.

15 Gleicher Lohn der Fraufür gleiche Leistung', München, Recht der Arbeit, núm. 4, abril de 1950, p. 121.

16 El término fue acuñado por primera vez por C. F. Gerber V. en sus obras Über öffentliche Rechte y Grundzüge des deutschen Staatsrechts, traducidas al italiano Sui diritti pubblici y Lineamenti di diritto pubblico tedesco, respectivamente, ambas en C. F. Gerber, V., Diritto pubblico, Milán, Giufrè Editore, 1971 (trad. italiana de P. Luigio Lucchini); pero fue principalmente Jellinek, G., en su System der subjektiven öffentlichen Rechte, quien desarrolló esta construcción teórica que transformó la concepción original de los derechos naturales de las revoluciones liberales del siglo XVIII para adaptarlos al funcionamiento del Estado de derecho posrevolucionario.

17 Ibidem, pp. 30 y 31.

18 Ibidem, pp. 92 y 93. 
Desde esta perspectiva, los derechos públicos subjetivos serán pretensiones jurídicas del individuo frente al Estado ${ }^{19} \mathrm{y}$ se concebirán, entonces sí, como meros límites al poder estatal. Concepción que se aleja de la idea recogida en las declaraciones del siglo XVIII, que los entendió como derechos naturales. ${ }^{20}$

La noción de los derechos públicos subjetivos morirá junto con la del Estado liberal; nacerá el Estado social de derecho y con él una nueva percepción de los derechos fundamentales que se adecuará a las nuevas necesidades y formas de organización social y económica.

Precisamente, el segundo argumento para desechar el origen histórico de los derechos fundamentales como razón suficiente para negar su eficacia horizontal, consiste en reconocer que éstos, como los conocemos hoy en día, ${ }^{21}$ son en realidad producto de una evolución de más de 200 años. ${ }^{22}$ En esta nueva concepción, la Drittwirkung constituye una nota esencial de su significado. ${ }^{23}$ H. P. Schneider lo dijo claramente:

19 Ibidem, p. 96; del mismo autor Teoría general del Estado, trad. de F. De los Ríos, Buenos Aires, Albatros, 1970, p. 313.

20 Véase al respecto Venegas Grau, M., op. cit., nota 10, p. 123.

21 P. Cruz Villalón dice que "los derechos fundamentales, tal como hoy los conocemos, hacen su aparición inicial en el Estado constitucional en un documento frecuentemente diferenciado de la propia Constitución (paradigmáticamente, la Declaración de Derechos del Hombre y del Ciudadano promulgada por la Asamblea Nacional Francesa el 26 de julio de 1789), para incorporarse pronto a los propios textos constitucionales, aunque sin perder nunca su propia identidad en el interior de los mismos". Op. cit., nota 4, p. 108. Debemos discernir con este autor, pues aunque es cierto que los derechos fundamentales aparecen por primera vez en las declaraciones de derechos del siglo XVIII, no se puede afirmar que éstos son los mismos desde entonces hasta nuestros días. Ello sería negar su evolución histórica, su paso por Francia como libertades públicas y por Alemania como derechos públicos subjetivos, hasta llegar a la noción actual que dista de la de hace más de 200 años y que es producto de este devenir en el tiempo.

22 Esta nueva concepción de los derechos nacerá después de la Segunda Guerra Mundial, principalmente con la Ley Fundamental de Bonn de 1949 como respuesta a determinadas vivencias históricas. Los artículos 1o. y 19 de la Ley Fundamental de Bonn contendrán las características esenciales de los derechos fundamentales. Véase al respecto Cruz Villalón, P., "Formación y evolución de los derechos fundamentales", $R E D C$, núm. 25,1989 , p. 62.

23 Negar la existencia de la Drittwirkung es desvirtuar la concepción actual de los derechos fundamentales. A. Bleckmann ha llegado a afirmar que la Drittwirkung representa ya la función primaria de los derechos fundamentales. "Neue Aspekte der Drittwirkung der Grundrechte", DVBL, 103, Jahrgang, FET 19, 1988, p. 942. 
lo que ha ido surgiendo de las necesidades de cada etapa histórica constituye hoy el status de derechos fundamentales democráticos. En su multiplicidad de niveles funcionales, los derechos fundamentales poseen hoy en primer término el carácter de conferir status: determinar, asegurar o limitar la posición jurídica del individuo en sus bases y en sus relaciones jurídicas con otros individuos. ${ }^{24}$

\section{El Estado social de derecho y la eficacia horizontal de los derechos}

Varias de las Constituciones que nacen después de la Segunda Guerra Mundial han introducido en sus textos el concepto de Estado social de derecho, como es el caso del artículo 20, fracción I, de la Ley Fundamental de Bonn, el artículo 2o. de la Constitución francesa de 1958, el artículo 1o., inciso 1, del proyecto de Constitución de la Confederación Suiza elaborado en 1977, el artículo 79 de la Ley Suprema del Perú, así como el artículo 1.1 de la Constitución Española, entre otras.

Se entiende por Estado social de derecho aquel en el que valiéndose frecuentemente de técnicas provenientes del Estado de derecho, se promueve la consecución de una igualdad y libertades reales y efectivas para los individuos y los grupos en que éstos se integran. ${ }^{25}$ En otros términos, es el Estado en el que la sociedad se protege por él y no frente a él. ${ }^{26}$

En contraposición al Estado liberal, donde la Constitución era un elemento limitador del poder político y los derechos fundamentales en ella recogidos se concretizaban con una abstención del poder público en la esfera jurídica del particular, en el Estado social y democrático de derecho la Constitución se concibe como un norma reguladora de la convivencia

24 Schneider, H. P., "Derechos fundamentales en el Estado constitucional democrático", Revista de Estudios Políticos, núm. 7, 1985, p. 13.

25 Jiménez Campo, J., "Estado social y democrático de derecho”, Diccionario del Sistema Político español, Madrid, 1984, p. 276. Esta fórmula es recogida en el artículo 92. del texto constitucional: "Corresponde a los poderes públicos promover las condiciones para que la libertad y la igualdad del individuo y de los grupos en que se integran sean reales y efectivas".

26 Huber, E. R., Rechtsstaat und Sozialstaat in der modernen Industriegeseelschaft, 1968, citado por García Cotarelo, J., Diccionario del Sistema Politico Español, cit., nota anterior, p. 271. 
social de la que dimanan indirectamente derechos y obligaciones, ${ }^{27}$ y los derechos fundamentales en ella recogidos, se concretizan ya no con una falta de acción del Estado, sino a través de una conducta positiva de éste en aras de garantizar los derechos que propugna. ${ }^{28}$

Si la noción actual de los derechos fundamentales se da en el marco de un Estado social de derecho, ${ }^{29}$ se deduce que su vigencia surte efectos no sólo en las relaciones verticales (del particular con el Estado), sino también en las relaciones sociales, ${ }^{30}$ y que el Estado debe garantizarlos.

La Constitución Española ha adoptado por esta fórmula, como ya lo decíamos, en sus artículos 1.1 y 9.2, y el Tribunal Constitucional la ha confirmado en varias sentencias. Basta mencionar, a manera de ejemplo, la STC 18/1984 en su FJ 3o., que dice expresamente:

La configuración del Estado como social de derecho viene así a culminar una evolución en la que la consecución de los fines de interés general no es absorbida por el Estado, sino que se armoniza en una acción mutua EstadoSociedad, que difumina la dicotomía derecho público-privado y agudiza [tanto] la dificultad de calificar determinados entes, cuando no existe calificación legal, como [la] de valorar la incidencia de una nueva regulación sobre su naturaleza jurídica.

Más adelante, en su FJ 6o., esta misma sentencia señala que:

la sujeción de los poderes públicos a la Constitución (artículo 9.1) "se traduce en un deber positivo de dar efectividad a tales derechos en cuanto a su vigencia en la vida social". La petición del principio es evidente: habría un deber de los poderes públicos de "dar efectividad" a los derechos fundamentales

${ }^{27}$ García Morillo, J., La protección judicial de los derechos fundamentales, Valencia, Tirant lo Blanch, 1994, p. 197.

28 Véase en este sentido Böckenförde, E. W., Sobre la situación de la dogmática de los derechos fundamentales tras 40 años de Ley Fundamental. Escritos sobre derechos fundamentales, trad. de J. L. Requejo Pagués, e I. Villaverde Menéndez, Baden-Baden, 1993, pp. 114-116.

29 Aunque García Torres, J. y Jiménez-Blanco, A., señalan que en efecto la Drittwirkung se deduce de la concepción del Estado social de derecho, consideran que invocar este argumento (el del Estado social de derecho) carece de verdadero peso jurídico. Derechos fundamentales y relaciones entre particulares. La Drittwirkung en la jurisprudencia del Tribunal Constitucional, Madrid, Civitas, 1986, pp. 100 y 101.

30 Idem. 
"en cuanto a su vigencia en la vida social" que deriva del artículo 9.1 de la Constitución.

\section{La dimensión objetiva de los derechos fundamentales}

Los derechos fundamentales contenidos en las Constituciones normativas de los Estados sociales y democráticos de derecho, que nacen después de la Segunda Guerra Mundial, ya no son concebidos únicamente como límites, prerrogativas o potestades del titular del derechos respecto al poder del Estado, sino también como principios y valores objetivos de todo el ordenamiento jurídico.

El Tribunal Federal Constitucional alemán ha dicho en este sentido que: "las normas iusfundamentales contienen no sólo derechos subjetivos de defensa del individuo frente al Estado, sino que representan, al mismo tiempo, un orden valorativo objetivo..."; 31 y como lo recuerda también el ATC 382/1996:

los derechos fundamentales, si bien continúan concibiéndose primordialmente como derechos subjetivos de defensa frente al Estado, presentan además una dimensión objetiva, en virtud de la cual operan como componentes estructurales básicos que han de informar el entero ordenamiento jurídico.

Esta nueva dimensión, como valores, que se le ha atribuido a los derechos fundamentales, ha sido denominada objetiva, y puede ser definida como el contenido de los derechos fundamentales, que aunado al subjetivo, es constituido por normas objetivas de principio (objektive Grundsatznormen) y decisiones axiológicas (Wertenstscheidungen), ${ }^{32}$ que representan el sistema de valores y principios concretos de una sociedad (sistema cultural), y se convierten - en consecuencia-, en la razón y fundamento del Estado, ${ }^{33}$ en tanto éste los reconoce y procura.

R. Alexy define la dimensión objetiva de los derechos como el resultado de hacer una triple abstracción de la prerrogativa fundamental que elimine completamente su contenido jurídico-subjetivo. Para este autor:

31 BVerfGE 39, 1 (41).

32 Böckenförde, E. W., Escritos sobre derechos fundamentales, trad. de J. L. Requejo e I. Villaverde, Baden-Baden, Nomos, 1993, p. 95.

33 Smend, R., "Verfassung und Verfassungsrecht", Teoría de la Constitución, Madrid, Alianza, 1982, p. 170. 
"si $a$ tiene frente al Estado (e) un derecho a $G(\operatorname{Rae} G)$, entonces $e$ tiene frente a $a$ un deber con respecto a $G(\mathrm{OeaG})$ ". ${ }^{34}$ En otras palabras, el reconocimiento de los derechos como valores objetivos impone al Estado mandatos de actuación y deberes de protección respecto a todos los destinatarios de la Constitución, ya sean públicos o privados.

La concepción de los derechos como valores objetivos obedece a la transformación del significado de los catálogos de derechos consignados en las Constituciones a partir de la Segunda Guerra Mundial, que de ser aspiraciones políticas o directrices no vinculantes en el siglo XIX, pasan a ser un sistema de preceptos. ${ }^{35}$

La ampliación del contenido de los derechos fundamentales a su dimensión objetiva puede entenderse como respuesta a los regímenes nacionalsocialista y a la quiebra del positivismo jurídico. Y son precisamente la jurisprudencia y la doctrina alemana las que, tratando superar una etapa histórica detestable, inician el peregrinaje de la construcción teórica de las normas objetivas de principios o decisiones axiológicas de los derechos fundamentales.

La Ley Fundamental de Bonn (artículo 1.3) se refiere a la forma y al contenido de las prerrogativas subjetivas, sin definir o incluir una nueva faceta, pero al interpretar dicha Ley, la jurisprudencia alemana redimensiona los derechos fundamentales dotándolos de un contenido objetivo sin transformar su contenido de prerrogativas fundamentales; es decir, aunado a su carácter subjetivo se les reconoce un contenido como normas objetivas de principio.

Ahora bien, es preciso señalar que el reconocimiento de la dimensión objetiva de los derechos fundamentales trae consigo determinadas consecuencias en el ordenamiento jurídico, que son: el efecto irradiación o expansión de los derechos; el deber de protección, y la que interesa a efectos de este trabajo: la eficacia frente a terceros.

El efecto de expansión de los derechos fundamentales significa que las potestades fundamentales en tanto normas objetivas de principio influyen amplia y materialmente en todas las esferas del sistema jurídico,

34 Alexy, R., Teoría de los derechos fundamentales, Madrid, Centro de Estudios Constitucionales, 1993, p. 509.

35 Vega, P. de, "Dificultades y problemas para la construcción de un constitucionalismo de la igualdad (el problema de la eficacia horizontal de los derechos fundamentales)", Anuario de Derecho Constitucional y Parlamentario, Murcia, núm. 6, 1994, p. 41. 
por tanto, son normas que no se limitan a regular la relación inmediata Estado-ciudadano, sino que rigen con validez universal, en todas direcciones; aún más, su contenido jurídico fundamental impone parámetros al Estado y a la sociedad en su conjunto.

Como consecuencia de este efecto irradiación, en tanto los derechos fundamentales son valores de la sociedad, se entiende que son observables también por los individuos en sus relaciones privadas, o sea despliegan sus efectos frente a particulares y ya no sólo frente al Estado.

Y por último, si hemos dicho que los derechos fundamentales en su dimensión objetiva son valores de toda la sociedad y legitiman la existencia del Estado, éste debe en consecuencia dar efectividad a su contenido. Obligación que se hace exigible tanto al legislador como a la administración y a los jueces, de acuerdo al ámbito de sus competencias. R. Alexy considera además que este deber genera simultáneamente un derecho a la protección, es decir, la potestad subjetiva que tiene el titular del derecho fundamental frente al Estado para que éste lo proteja de intervenciones de terceros. ${ }^{36}$

En resumen, como valores del ordenamiento que son los derechos fundamentales en su nueva dimensión objetiva, éstos irradian sus efectos en todo el sistema normativo y también en las relaciones particulares, convirtiéndose además en deberes de protección hacia el Estado. ${ }^{37}$ Esto implica que el poder público está vinculado a los derechos de dos maneras: por un lado, en su sentido tradicional abstencionista de no lesionar la esfera jurídica protegida por los derechos y, por el otro, en su dimensión objetiva, respecto de la cual deberá procurar que el disfrute de los dere-

36 Alexy, R., Tres escritos sobre derechos fundamentales y la teoría de los principios, trad. del alemán de Carlos Bernal Pulido, Universidad Externado de Colombia, 2003, nota 59 , pp. 435 y 436.

37 Böckenförde, E. W., señala: "Los derechos fundamentales como normas de principio o decisiones axiológicas denotan un contenido normativo determinado que exige ser realizado; no son derechos que persigan la abstención, sino que pretenden la actuación y la protección de estos contenidos". Más adelante, afirma este mismo autor, que: "El deber de protección del Estado es general. No sólo prohíbe - evidentemente- intervenciones estatales directas en la vida que se está gestando, sino que obliga también al Estado a situarse ante esta vida en términos de protección y promoción, es decir, a protegerla frente a ataques antijurídicos por parte de otros". Sobre la situación de la dogmática de los derechos fundamentales tras 40 años de Ley Fundamental, cit., nota 28, pp. 114 y 115. 
chos sea real y efectivo en todos los sectores del ordenamiento jurídico en el que desplieguen sus efectos. ${ }^{38}$

\section{Reorientación del centro de gravedad del poder}

Si la función de los derechos fundamentales en el Estado liberal, aunque no la única, era limitar al Estado como detentador del poder, la realidad de hoy nos muestra que además del Estado, existen otros entes detentadores de poderes sociales y económicos capaces, por esa razón, de violar los derechos fundamentales de aquellas personas que se encuentran de facto en una situación desfavorable o de indefensión.

El contexto social del mundo en el que vivimos, con la aparición de la sociedad industrial y la estructura económica que ella conlleva, ha dado lugar al nacimiento de una tercera categoría de sujetos, como los sindicatos, las asociaciones profesionales o las grandes empresas que acumulan casi siempre un enorme poderío material y/o económico. El creciente protagonismo de estos grupos en la vida actual ha reorientado el centro de gravedad del poder y consiguientemente de los peligros para los derechos fundamentales. En este sentido, H. C. Nipperdey afirmó que las amenazas sobre los derechos de los individuos no proceden ya únicamente del Estado como detentador de la fuerza, sino que también pueden provenir de (poderes sociales) y de particulares: (frente a todos ellos protegen los derechos fundamentales). ${ }^{39}$ Secundando esta idea, el mismo P. Häberle ha afirmado que: "con las transformaciones sociales, el poder 'cuasi-público' de determinados grupos representan un peligro para el individuo mayor que el que dimana del poder del Estado". ${ }^{40}$

Estas desigualdades de hecho en las relaciones y conformaciones socioeconómicas de poder pueden impedir el surgimiento de la libertad como libertad real, haciendo que no pueda verificarse la realización de la libertad jurídicamente garantizada. ${ }^{41}$ En este sentido, la autonomía de la

38 Venegas Grau, M., op. cit., nota 10, p. 173.

39 Nipperdey, H. C., Gleicher Lohn der Frau für gleiche Leistung, Recht der Arbeit, cit., nota 15 , p. 125.

40 Häberle, P., Die Verfassung des Pluralismus, Berlín, Könisgstein, Athenäum, 1980, p. 177.

41 Böckenförde, E. W., “Aseguramiento de la libertad frente al poder social. Esbozo de un problema", op. cit., nota 32, p. 85. Para L. v. Stein, "La libertad es una libertad real 
voluntad que tanto se preconiza como ejercicio de la libertad individual, no se ejerce con plenitud a la hora de obligarse.

Ha sido la quiebra de esta convicción igualitaria — sostiene L. Prieto Sanchís - la que ha promovido la extensión de los derechos fundamentales al ámbito privado, la que ha permitido preguntarse si acaso los derechos no deben ser también preferentes o, al menos, protegibles en el entramado de las relaciones jurídicas nacidas de la autonomía privada; pues si la resistencia de los derechos humanos se explica por la exigencia de preservar los derechos naturales una vez constituido el Estado y, por tanto, un poder superior al de cualquier individuo, la constatación de que esa desigualdad es característica también de la sociedad civil parece postular asimismo la formulación de unos derechos resistentes que sirvan como barrera protectora de la libertad frente a los sujetos privados. ${ }^{42}$

Precisamente uno de los principales argumentos de los defensores de la Drittwirkung inmediata (que se analizará adelante) es la igualdad ficticia que rige las relaciones privadas y que se funda en la idea de que el consentimiento, fiel reflejo de la voluntad de las partes, basta para impedir que éstas limiten de forma inaceptable su libertad. Se presume que la libertad queda garantizada en la medida en que las partes han aceptado esas limitaciones en el ejercicio de su voluntad. Sin embargo, la libertad contractual así concebida es una libertad meramente formal e ignora la realidad social que generalmente impone a aquellos que se encuentran en una situación de inferioridad (una dependencia que contradice las ideas fundamentales de la Constitución). ${ }^{43}$ De hecho, los partidarios de la Drittwirkung mediata (que también se explicará más adelante), le atribuyen una especial relevancia al hecho de que una de las partes del contrato ostente una posición de predominio respecto a la otra y admiten que "los sujetos privados poderosos no pueden ser tratados como cualquier otro individuo y que se deben considerar ilícitas en las relaciones privadas las

tan sólo para aquel que posee las condiciones mismas, los bienes materiales y espirituales como presupuesto de la autodeterminación", Geschichte der sozialen Bewegung in Frankreicht von 1789 bis auf unsere Tage, vol. 3, Munich (De Salomon), 1959, p. 104.

42 Prieto Sanchís, L., op. cit., nota 8, pp. 208 y 209.

43 Nipperdey, H. C., "Freie Entfaltung der Persönlichkeit", en Bettermann, H. C. et al., Die Grundrechte. Handbuch der Theorie und Praxis der Grundrechte, Berlín, Duncker \& Humblot, 1962, t. IV, 2, p. 753. 
diferencias de trato con las restricciones que atenten contra la dignidad de las personas". 44

Así pues, si los derechos fundamentales son límites al poder, y hoy en día el poder susceptible de interferir en la libertad del particular no es ya sólo el del Estado, sino también el privado, resulta coherente expandir la función de protección frente al poder en las relaciones privadas. Al hacerlo, no se está desvirtuando, sino llevando hasta sus últimas consecuencias el significado de los derechos como barreras al poder - frente a todo poder- ${ }^{45} \mathrm{o}$ dicho de otra forma, si el Estado ya no es el único detentador el poder, no es tampoco el único destinatario de los derechos fundamentales. Por eso F. J. Ansuátegui propone presentar estos derechos ya no como "límites al poder" sino como "límites a los poderes". 46

Esta protección de los individuos ante la desigualdad fáctica existente en el tráfico jurídico, suele ser, en términos de J. García Torres y A. Jiménez Blanco el punto de partida usual de todo trabajo bien educado en materia de Drittwirkung. ${ }^{47}$ Aunque la realidad, como sostienen estos mismos autores, es más complicada y tiende a presentarse como un conflicto de poderes sociales, en el que los derechos fundamentales están a favor de o, por lo menos, suelen ser invocados con éxito, por la parte no necesariamente menos poderosa en las relaciones horizontales. De ahí que deba hablarse, mejor que de derechos fundamentales frente a poderes sociales, de derechos fundamentales en relaciones particulares. Por eso dice J. García Morillo que los derechos fundamentales protegen a todos

44 Vieira de Andrade, J. C., Os Direitos fundamentais na Constituição Portuguesa de 1976, Coimbra, Libraría Almedina, 1987, p. 285.

45 Venegas Grau, M., op. cit., nota 10, p. 122.

46 Ansuátegui, F. J., "Derechos fundamentales, poder político, y poderes sociales", en Varios Autores, Direitos humanos: a promesa do século XXI, Porto, ELSA, 1997, p. 201. En el mismo sentido J. M. Bilbao Ubillos dice que: “en último término, la razón de ser de los derechos fundamentales es fijar ciertos límites al poder, de modo que el individuo tenga la posibilidad de reaccionar frente a los abusos que incidan en su esfera de libertad. Lo que ocurre es que en la tradición liberal sólo se contemplaba como hipótesis relevante la posible injerencia del Estado, dado que la Constitución le atribuía competencias cuyo ejercicio entraba en colisión tendencialmente, por su propia lógica, con esa esfera de autonomía individual", La eficacia de los derechos fundamentales, Madrid, Centro de Estudios Políticos y Constitucionales, 1997, p. 326.

47 García Torres, J. y Jiménez-Blanco, A., literalmente han dicho que: "la protección de los individuos frente al ejercicio del poder social, suele ser el punto de partida usual de todo trabajo bien educado en materia de Drittwirkung", op. cit., nota 10, p. 142. 
frente a todos. ${ }^{48} \mathrm{O}$ sea, que no sólo existe un sujeto detentador del poder frente a otro en desventaja, y que por esa razón el primero viole los derechos fundamentales del segundo, sino que estando en igualdad de condiciones, un particular puede violar los derechos fundamentales de otro, o aun el desfavorecido los derechos del aventajado.

\section{LAS TEORÍAS DE LA EFICACIA HORIZONTAL DE LOS DERECHOS}

Ha quedado demostrado pues, debido a la evolución histórica de los derechos, la importancia del Estado social y democrático de derecho y su concepción de los derechos como principios y valores del ordenamiento jurídico, así como por la reorientación del centro de gravedad del poder, que los derechos fundamentales son vigentes en las relaciones particulares. Pero la problemática que ha acaparado la discusión doctrinal de los últimos 60 años, se ha centrado más bien en determinar la modalidad o tipo de eficacia que los derechos fundamentales han de desplegar en el tráfico jurídico privado, si lo han de hacer de manera mediata (teoría de la mittelbare Drittwirkung), o bien, de manera inmediata (teoría de la unmittelbare Drittwirkung). Y resulta preciso analizar ambas teorías, pues parece ser que, más que contraponerse, como hasta el momento se ha predicado, pudieran ser complementarias.

\section{La eficacia mediata. La teoría de la mittelbare Drittwirkung}

La mittelbare Drittwirkung es producto de la dimensión objetiva de los derechos fundamentales, lo que significa, como ya dijimos, que el Estado tiene la obligación ya no sólo de abstenerse en la intromisión de la esfera jurídica de los particulares, sino también de garantizar su efectividad en las relaciones privadas, ${ }^{49}$ en tanto que los derechos fundamentales son ahora valores objetivos del ordenamiento jurídico. ${ }^{50}$

48 García Morillo, J., op. cit., nota 27, pp. 198 y 199.

49 Para Stein, los derechos fundamentales imponen al Estado "la obligación de configurar la situación jurídica de los terceros de acuerdo con éstos”, Stein, E., Derecho Político, Madrid, Aguilar, 1973, pp. 242 y 243.

50 Véase al respecto Maunz, T. y Dürig, G., Grundgesetz Kommentar, Band, V, Lfg. 20, marginal 29, p. 102. 
La forma en que el Estado concretizará este deber de hacer efectivos los derechos fundamentales (como valores objetivos) en las relaciones privadas, será mediante sus órganos. ${ }^{51}$ En primer lugar a través del legislador y de manera subsidiaria con la intervención del juez. Así, cuando ocurra la violación de un derecho fundamental en una relación particular, la infracción será imputable al Estado, ya sea en su órgano legislativo o judicial, ${ }^{52}$ por no haber dispensado la protección esperada.

En otras palabras, lo que propone la Drittwirkung mediata, es que el legislador, con base en el principio de proporcionalidad, regule el alcance de los derechos fundamentales en las relaciones particulares, $\mathrm{y}$ en caso de ausencia legislativa, el juez resuelva el caso concreto teniendo en cuenta la influencia de los derechos fundamentales entendidos como valores sobre las normas de derecho privado. ${ }^{53}$

Desde esta perspectiva, quien en realidad está directamente constreñido por los derechos fundamentales es el poder público y no el particular. Si este último se encuentra vinculado a los derechos fundamentales es de forma indirecta, es decir, en la medida en que los derechos son decisiones valorativas objetivas (objektive Wertentscheidungen) y no derechos subjetivos que un particular ostenta frente a otro. Si los individuos pudieran invocar las libertades constitucionales contra las normas del derecho privado y contra los compromisos que han asumido a través de pactos privados en el ejercicio de su autonomía, ${ }^{54}$ consideran los defensores de esta teoría, se atentaría contra la misma autonomía de la voluntad y se estaría alterando la estructura del ordenamiento jurídico privado, ${ }^{55}$ además

51 Quadra-Salcedo, T., El recurso de amparo y los derechos fundamentales de las personas en las relaciones entre particulares, Madrid, Civitas, 1981, p. 51.

52 Veáse Venegas Grau, M., op. cit., nota 10, p. 147.

53 Ibidem, p. 230.

54 Scheuner, U., "Fundamental rights and the protection of the individual against social groups and powers in the constitutional system of the Federal Republic of Germany", en Varios Autores, René Cassin amicorum discipulorumque liber, cit., nota 2, p. 265 .

55 Canaris, C. W., en contraposición a la teoría de la eficacia inmediata, sostiene que: "la presencia de un poder social no constituye un problema independiente, sino que se inscribe dentro de la cuestión, mucho más amplia, de la vulneración de la paridad contractual, para cuya solución el derecho facilita un gran número de instrumentos (desde los mecanismos clásicos del derecho privado dirigidos a garantizar la autonomía de las partes, hasta la protección de la competencia o la regulación de los derechos de los consumidores pasando por los convenios colectivos). En consecuencia, no resulta necesario (ni 
de desvirtuar el origen histórico de los derechos como límites al poder del Estado.

\section{La mediación del legislador}

El órgano público a través del cual el Estado responde con su mandato constitucional de proteger los derechos fundamentales garantizándolos como valores y bienes jurídicos del ordenamiento jurídico, es el legislativo; ${ }^{56}$ lo cual responde a legitimidad democrática que posee y en tanto es el representante de la soberanía nacional. ${ }^{57}$ Según H. H. Klein, "sólo a través de la ley o sobre la base de una ley se encuentra el Estado facultado para combatir activamente las conductas privadas que suponen una amenaza para un bien jurídico". .58

La forma en que el legislador concretizará la eficacia horizontal de los derechos fundamentales será tomando en cuenta los valores objetivos que éstos representan y adaptándolos a la propia estructura de las relaciones privadas debiendo moverse entre el contenido esencial de los derechos y la garantía de la autonomía privada. ${ }^{59}$

aconsejable) recurrir a una aplicación directa de los derechos fundamentales". "Grundrechte und Privatrecht", Archiv für die Civilistische Praxis, 3, 1984, p. 207. No obstante, al defender la autonomía de la voluntad de las partes, tampoco debemos olvidar que, como dice Hesse, "un derecho civil que descansa sobra la protección de la personalidad y sobre la autonomía privada forma parte de las condiciones fundamentales del orden constitucional de la Ley Fundamental. La libertad privada de la persona, que el derecho civil presupone y para cuya salvaguardia y desarrollo dispone normas y procesos jurídicos, es requisito indispensable para las decisiones responsables y para la posibilidad misma de decidir. Y esta última sustenta a su vez el libre desarrollo de la personalidad recogido como derecho fundamental en la Constitución”. Hesse, K., Derecho constitucional y derecho privado, trad. de I. Gutiérrez, Madrid, Civitas, 1995, p. 86.

56 Véase Canaris, C. W., ibidem, p. 225.

57 Quadra-Salcedo, El recurso de amparo..., cit., nota 51, p. 52.

58 Klein, H. H., Die grundrechtliche Schutzpflicht, Deutsches Verwaltungsblatt, núm. 9, 1o. de mayo de 1994, p. 491; Cruz Villalón P. de igual forma cree que: "es ... el legislador el llamado a determinar, en la medida de lo posible, cuáles son las consecuencias que para las relaciones entre particulares se derivan del hecho de que la Constitución haya reconocido como derechos fundamentales, por ejemplo, la libertad de expresión, el derecho a la intimidad o el principio de igualdad", La llamada "Drittwirkung" de los derechos fundamentales, cit., nota 21, p. 2219.

59 Bilbao Ubillos, J. M., op. cit., nota 46, pp. 290 у 291. 
Nadie niega que la ley sea el medio idóneo para la configuración de los derechos fundamentales (tanto en las relaciones públicas como en las privadas) pero a nuestro parecer, resulta difícil sostener que su operatividad en las relaciones particulares dependa única y exclusivamente de la voluntad del legislador, pues éste no puede contemplar todas las situaciones ni todos los conflictos existentes ${ }^{60}$ y su falta de actuación no puede derivar en la inexistencia de un derecho. El mismo Böckenferde, defensor de la mitelbare Drittwirkung, ha dicho que la realización de los derechos fundamentales, "no puede depender de una configuración infraconstitucional suficiente del ordenamiento jurídico privado". ${ }^{61}$

Por lo demás, al defender esta postura se estaría concibiendo a los derechos fundamentales en las relaciones particulares, ya no como tales, como constitucionales, sino como meramente legales. ${ }^{62}$

\section{La mediación del juez}

La ley es el medio idóneo para configurar la vinculación de los derechos fundamentales en las relaciones particulares, según sostienen los partidarios de la mittelbare Drittwirkung, pero ellos mismos reconocen, como lo acabamos de decir respecto de Böckenferde, que el legislador no puede prever todas las circunstancias, por lo que ante la falta de legislación, o en caso de una ley imprecisa, el juez, de manera subsidiaria, resolverá los conflictos de derechos fundamentales que se susciten entre particulares.

El juez actuará interpretando las normas de derecho privado a la luz de los derechos fundamentales concebidos como valores objetivos; ${ }^{63}$ lo que significa que los derechos entendidos como subjetivos son transformados en valores para que el juez pueda ponderarlos.

El Tribunal Constitucional alemán recurrió a esta teoría por primera vez en el caso Lüth-Urteil, ${ }^{64}$ en el que un periodista llamado Eric Lüth,

60 Ibidem, p. 295; véase también la STC 112/1989 FJ 2o., de 19 de junio, en la que el Tribunal Constitucional reconoció que la intervención del legislador no siempre es necesaria.

61 Böckenförde, E. W., op. cit., nota 28, p. 113.

62 Bilbao Ubillos, J. M., op. cit., nota 46, p. 297.

63 Quadra-Salcedo, El recurso de amparo..., cit., nota 51, pp. 53 y 54.

64 BverfG 7, 198. 
llamó al boicot contra una película realizada por un productor simpatizante, en su tiempo, con el régimen nacional socialista. El productor (Urteil) reaccionó y consiguió del juez una orden para que el periodista se abstuviese de seguir llamando al boicot. Ante esta decisión, el periodista apeló la decisión ante el Tribunal Constitucional, que recordó que la libertad de expresión no se aplica directamente a las relaciones entre particulares; no obstante, consideró que la sentencia del juez ordinario vulneraba el derecho fundamental del señor Lüth toda vez que éste (el juez) se encontraba vinculado por los derechos fundamentales en el sentido que debía de tener en cuenta a la hora de interpretar y aplicar las normas de derecho privado, la influencia de los derechos fundamentales en el campo de la relaciones de carácter civil o laboral, al no hacerlo, al no valorar en su justa medida el efecto irradiación que un determinado derecho fundamental despliega en una relación jurídica privada concreta, el juez incurrió en su vulneración. Así, el Tribunal de Karlsruhe reconoció la vinculación de los derechos fundamentales en el tráfico jurídico privado.

Esta postura ha llevado a T. Quadra-Salcedo a afirmar que los derechos fundamentales se han degradado,

en el sentido de que han dejado de configurarse como derechos subjetivos perfectamente delimitados y oponibles frente a todos para transformarse en simples valores y principios objetivos de los que nadie es titular concreto como para poderlos exigir como si de un derecho se tratase; o si se quiere decir de otra manera: porque no aparecen claramente delimitados y exigen una concreción judicial se piensa que ya no son derechos subjetivos, sino meros valores objetivos. ${ }^{65}$

Por su parte, J. M. Bilbao Ubillos ha dicho que esta teoría de la eficacia mediata a través del juez es en realidad "ilusoria", ${ }^{66}$ pues desde una perspectiva práctica, no importa cuál ha sido el método de solución del juez, sino que el afectado se vea o no resarcido en la violación de su derecho fundamental, ya sea que el juez haya considerado que la violación haya atentado contra un valor objetivo o que se haya violado un verdadero derecho subjetivo. En el fondo, lo que se defiende es un derecho subjetivo

65 Quadra-Salcedo, T., El recurso de amparo..., cit., nota 51, pp. 54 y 55

66 Bilbao Ubillos, J. M., op. cit., nota 46, p. 318. 
de la persona. ${ }^{67}$ Además de que no ve, este autor, como tampoco vemos nosotros, que exista alguna diferencia entre la mitelbare Drittwirkung con mediación del juez y el principio general de interpretación de todas las normas del ordenamiento conforme a la Constitución. ${ }^{68}$

Por otro lado, el mismo J. M. Bilbao Ubillos señala agudamente que:

para concretar el alcance de un derecho fundamental cuando el conflicto se suscita en el ámbito de las relaciones jurídico-públicas, también es necesaria la mediación judicial y no por eso su eficacia es mediata, ni la interpretación que hace el juez es desde una óptica del derecho como un valor objetivo. ${ }^{69}$

Debe concluirse pues, que la teoría de la eficacia mediata, no es tal (mediata) debido a la intervención de un órgano del Estado, ya sea el legislativo o el judicial, sino en atención a la interpretación que éste órgano hace de los derechos fundamentales como valores objetivos del ordenamiento jurídico y por la influencia que como tales despliegan en las relaciones jurídico-privadas.

\section{La eficacia inmediata. La teoría de la unmitelbare Drittwirkung}

En contraposición a la teoría de la eficacia horizontal mediata, la unmitelbare Drittwirkung defiende que los derechos fundamentales no son valores sino verdaderos derechos subjetivos contenidos en la Constitución y, como tales, exigibles directamente por el individuo que los ostenta frente a sus semejantes, sin que sea necesaria la mediación de un órgano estatal. ${ }^{70}$

67 En el caso Lüth, por ejemplo, si bien la solución que se dio, se debió a que según el Tribunal Constitucional, el juez ordinario no contempló la normativa civil desde la perspectiva de los valores que los derechos fundamentales representaban, lo que importó para el señor Lüth fue que la violación de su derecho fundamental se haya reconocido y el daño resarcido.

68 Bilbao Ubillos, J. M., op. cit., nota 46, p. 313.

69 Ibidem, p. 321.

70 Principalmente nos estamos refiriendo a la intervención del legislador, pues como se verá mas adelante, tanto en la mittelbare Drittwirkung como en la unmittelbare Drittwirkung, precisan de la intervención del juzgador para concretar el derecho fundamental, lo que variará será la interpretación que de él se haga. 
No se trata de negar la intervención del legislador para que configure el alcance de los derechos fundamentales en las relaciones privadas, sino que, como dijimos arriba, no puede considerarse que un derecho no existe, o no surte efectos frente a particulares, simplemente porque no haya una ley que así que lo establezca. ${ }^{71}$ La obligación de respetar los derechos fundamentales por los ciudadanos surge y emana directamente de la Constitución y no sólo de las normas de desarrollo de ésta. ${ }^{72}$

Es innegable que siempre que exista una ley que regule la eficacia de un derecho fundamental en una determinada relación privada, el conflicto deberá resolverse según lo previsto en dicha norma, pero si no hay un precepto específico que permita solucionar el caso concreto, el derecho fundamental que se pretende defender y que está recogido en la Constitución, es vinculante directamente como un derecho subjetivo de una parte frente a la otra, no como un criterio hermenéutico al que se deba recurrir para descifrar su influencia en el derecho privado. ${ }^{73}$

La STC 39/1983, de 17 de mayo, FJ 2o., ha señalado que: "los derechos fundamentales y libertades públicas que reconoce la Constitución son de aplicación directa, sin que sea necesario para su efectividad un desarrollo legislativo". A nuestro entender, éste desarrollo legislativo no debe ser necesario para configurar la eficacia horizontal de los derechos fundamentales, como no lo es para su eficacia vertical. En otras palabras, si los derechos fundamentales son vinculantes frente al Estado de manera directa, es decir, sin necesidad de previsión legal, ¿por qué resulta necesario que haya una ley que los configure en las relaciones particulares? ${ }^{74}$

Debe reconocerse que los derechos fundamentales se desarrollan en el seno de la sociedad y afectan de forma habitual las relaciones civiles,

71 El mismo Dürig reconoce que canalizar la colisión de derechos a través de la reserva de la ley no conduce a una mayor claridad, porque la reserva legal se acomoda mal a las exigencias de la elasticidad del derecho privado Poyal Costa, A., "La eficacia de los derechos humanos frente a terceros", Revista de Derecho Político, Madrid, Universidad Nacional de Educación a Distancia, núm. 34, 1991, pp. 189-221.

72 Quadra-Salcedo, T., El recurso de amparo..., cit., nota 51, p. 70.

73 En el mismo sentido véase Venegas Grau, M., op. cit., nota 10, pp. 198 y 199.

74 Coincidimos con Bilbao Ubillos en que la intervención del legislador no es un trámite indispensable (como no lo es en el campo de la relaciones individuo-Estado). "No parece compatible la afirmación de que los derechos fundamentales sólo operan (frente a particulares) cuando el legislador así lo decide”, op. cit., nota 46, p. 297. 
mercantiles, laborales y en general, la vida social de las personas. ${ }^{75}$ Qué sentido tendría hablar de una garantía de libertad o de igualdad contra el Estado, si la verdad es que la libertad, la igualdad y demás derechos fundamentales se desenvuelven en el marco de las relaciones sociales. Como afirma R. Naranjo de la Cruz, si las libertades no se ostentan frente a los particulares, nunca podrán ser reales, ni mucho menos efectivas. ${ }^{76}$

\section{La unmittelbare Drittwirkung no es predicable de todos los derechos}

Defender la eficacia horizontal directa de los derechos fundamentales debe ser matizado, pues como sostiene H. C. Nipperdey que la eficacia horizontal no es predicable de todos los derechos, por lo que en cada caso, habrá que analizar si procede o no hablar de Drittwirkung. ${ }^{77}$

Será la delimitación del ámbito protegido por cada derecho fundamental, lo que indique si despliega o no sus efectos en las relaciones particulares y, en su caso, hasta dónde llega dicha eficacia. ${ }^{78}$

Así, por ejemplo, hay derechos que por su propia naturaleza, despliegan más una eficacia frente a terceros que frente al mismo Estado, como es el caso de los derechos de la personalidad (el honor, la intimidad y la propia imagen), elevados a rango de derechos fundamentales en el artículo $18 \mathrm{CE}$, y que colisionan directamente con la libertad de expresión y el derecho a la información que poseen otras personas en virtud del artículo 20 de la CE. También el derecho a la cláusula de conciencia que tienen los periodistas, reconocido en el artículo 20 de la CE, es un derecho oponible principalmente frente a los medios de comunicación de los que los informadores forman parte; ni qué decir de los derechos laborales de sindicación y huelga recogidos en el artículo 28 de la CE y que constituyen un límite a la libertad de empresa. Por el contrario, existen otros

75 Balaguer Callejón, M. L., “Interpretación de la Constitución y ordenamiento jurídico", Madrid, Tecnos, 1997, p. 45.

76 Naranjo de la Cruz, R., Los límites de los derechos fundamentales en las relaciones particulares, Madrid, Boletín Oficial del Estado-Centro de Estudios Políticos y Constitucionales, 2000, p. 201

77 Nipperderdey, H. C., Freie Entfaltung der Persönlichkeit, Berlín, Dunker \& Humblot, Die Grundrechte, IV, 2, 1962, p. 752.

78 Naranjo de la Cruz, R., Los límites de los derechos fundamentales en las relaciones entre particulares... cit., nota 76, pp. 204 y 205. 
derechos fundamentales que son oponibles, en principio, sólo frente al Estado, como suele ocurrir con las garantías contenidas en los artículos 24 y $25 \mathrm{CE}$, que son las correspondientes al derecho penal y administrativo sancionador. ${ }^{79}$

\section{El protagonismo del juez no es atribuible únicamente a la unmittelbare Drittwirkung}

Al concebir los derechos fundamentales como derechos subjetivos que el individuo ostenta directamente frente a sus semejantes en sus relaciones particulares, ya sea con mediación legal o sin ella, se está otorgando al juez una capacidad concretizadora de éstos que pertenece en principio al legislador, ${ }^{80}$ según sostienen los detractores de la unmittelbare Drittwirkung. A lo que J. M. Bilbao Ubillos responde que, efectivamente, lo que pasa es que "cuesta trabajo asumir el creciente protagonismo del juez (que es, de hecho, 'el señor' de los derechos fundamentales)" $\mathrm{y}$ añade, que este protagonismo judicial no tiene por qué conducir a un caos, como no ocurre en los sistemas de case law; ${ }^{81}$ ni cabe hablar de usurpación de funciones cuando se considera que la actuación judicial es subsidiaria de la legislativa.

79 No son pocas las sentencias que han señalado expresamente que estas garantías son predicables únicamente frente al poder público y que han negado su protección en las relaciones privadas. La STC 18/1984 de 7 de febrero FJ 6o., señaló expresamente que estos derechos (los del artículo $24 \mathrm{CE}$ ) "sólo se tienen frente a los poderes públicos"; al igual que la STS de 9 de junio de 2001, FJ 1o., y la SAP de Ávila de 20 de mayo de 1998. En su Auto 293/1982, de 6 de octubre, FJ 6o., el Tribunal Constitucional sostuvo también que el principio de legalidad sólo se refiere a los delitos y faltas de naturaleza penal y a las infracciones administrativas. Véanse también las SSTC 69/1983, de 26 de julio; 96/1988, de 26 de mayo y 239/1988, de 14 de diciembre, 61/1990, de 23 de septiembre; 6/1995, de 10 de enero y la 120/1996, de 8 de julio.

80 Cruz Villalón, P., cree que "en la actual situación de neto protagonismo de la jurisdicción en la concreción de la Drittwirkung hay un elemento de anormalidad", Derechos fundamentales y derecho privado, en Varios Autores, La multipropiedad, Madrid, Academia Sevillana de Notariado, 1988, pp. 113 y 114.

81 Bilbao Ubillos, J. M., op. cit., nota 46, p. 301. En el mismo sentido, García Torres, J. y Jiménez-Blanco, A., reconocen que "(E)n el derecho constitucional español, la Drittwirkung, precisamente porque implica la elección de un proyecto general de sentido, se nos presenta como Richterrecht, derecho judicial o del juez", op. cit., nota 9, p. 143. 
De cualquier forma, este problema del protagonismo del juez, no es sólo atribuible a la unmittelbare Drittwirkung, sino también a la mittelbare Drittwirkung. Es más, en este segundo caso, el juez goza de una mayor discrecionalidad al concebir a los derechos fundamentales como valores a partir de los cuales se tratará de desentrañar el efecto que éstos ejercen en una determinada situación. Cuestión que en la realidad, acarrea mayor inseguridad jurídica y da al juez mayor protagonismo que el que pretenden prevenir los que defienden la mittelbare Drittwirkung. ${ }^{82}$

\section{La protección de la autonomía de la voluntad}

Otra crítica recurrente a la unmittelbare Drittwirkung, suele ser la que si el juez interpreta los derechos fundamentales como verdaderos derechos subjetivos, se está poniendo en riesgo la autonomía de la voluntad y, con él, al ordenamiento jurídico privado, como ya indicamos arriba. Sin embargo, debe recordarse que la autonomía no es más que la manifestación de la libertad y que la tesis de la eficacia inmediata procura más bien un reforzamiento de la autonomía privada y especialmente de la libertad contractual real pretendiendo mantenerla incluso frente a los poderes sociales y a las posiciones de poder fáctico de los particulares. ${ }^{83}$

\section{Conciliación de ambas teorías}

Más que discutir sobre cuál de las dos teorías debe prevalecer, es mejor considerar que ambas se complementan. Tanto una como la otra concuerdan en que la ley es el medio idóneo para la proyección horizontal de los derechos fundamentales, y que en caso de ausencia legislativa ambas teorías recurren a la mediación judicial. En la eficacia mediata, el juez considerará a los derechos como valores objetivos y desde ahí deducirá la influencia que como tales despliegan en el caso particular; en el caso de la eficacia inmediata, el juez interpretará los derechos como verdaderos derechos subjetivos y los ponderará con base en los principios de idonei-

82 Como sostiene Bleckmann A., "la objetivación de los derechos fundamentales permite al juez sustraerse del tenor literal de la norma que consagra un derecho fundamental, para resolver el conflicto en cuestión atendiendo únicamente al valor que subyace al derecho", Staatsrecht, II, p. 193.

83 Nipperderdey, H. C., op. cit., nota 77, p. 756. 
dad, necesidad y ponderación strico sensu. Pero en última instancia lo que importa es que el juez declare el derecho de uno u otro litigante. ${ }^{84}$

En un caso concreto, independientemente de cuál sea la teoría que se defienda, el conflicto se deberá resolver a través de una ponderación de los derechos enfrentados, una ponderación que en muchas ocasiones tendrá un resultado idéntico en uno y otro caso. Así, ante un pacto privado que vulnere un derecho fundamental, generalmente se declarará la nulidad del acuerdo, tanto si se considerase que lo pactado atenta contra un derecho fundamental específico, como si al violar ese derecho fundamental se esté conculcando algún valor objetivo, como la buena costumbre. ${ }^{85}$

El hecho de aceptar que los derechos fundamentales son valores objetivos del ordenamiento jurídico no implica desconocer que al mismo tiempo son derechos subjetivos y que como tales también despliegan sus efectos en las relaciones privadas. De hecho, H. C. Nipperdey consideraba que el efecto irradiación de los derechos fundamentales generaba una vinculación inmediata, no mediata, entre los particulares. ${ }^{86}$

Para algunos partidarios de la mittelbare Drittwirkung, como Böckenförde, la teoría inmediata puede ser subsidiaria de la mediata en aque1los supuestos en los que el derecho privado no ofrece ninguna opción. ${ }^{87}$ Para este autor queda claro que es el legislador el que debe configurar los derechos fundamentales en las relaciones horizontales, pero ante la ausencia de previsión legal se daría paso a la aplicación directa de los derechos en los casos concretos. ${ }^{88}$ Esta misma postura se encuentra en un autor como Stern, quien admite que se puede acudir directamente a los derechos fundamentales en defecto de una norma jurídico-privada. ${ }^{89}$

La intención que se persigue al conciliar ambas teorías no es otra que la de procurar en la mayor medida de lo posible el ejercicio real de los derechos fundamentales en el marco del Estado social y democrático de derecho en el que se inscriben.

84 Quadra-Salcedo, T., El recurso de amparo..., cit., nota 51, p. 59

85 Eckhold-Schmdt, F., Legitimation durch Begründung, Berlín, Dissertation, 1974.

86 Grundrechte und Privatrecht, Krefeld, Im Scherpe, 1961, pp. 5-27.

87 Véase Böckenförde, E.W., op. cit., nota 28, p. 113.

88 Idem.

89 Stern, K., Das Staatsrecht der Bundesrepublik Deutschland, vol. III, Allgemeine Lehre der Grundrechte, München, Beck, 1988, pp. 1558 y ss. 


\section{La eficacia horizontal de los derechos en el sistema} jurídico español

El desarrollo de la Drittwirkung, desde que se originó en la Alemania de la Segunda Postguerra y hasta nuestros días, ha sido inusitado. A tal grado que, como afirman J. García Torres y A. Jiménez-Blanco, ya no se trata de

un simple esclarecimiento de sentido (Sinndeutung) dentro de un "horizonte" o proyecto general de sentido. [Sino] que [r]epresenta, en sí misma, un nuevo "horizonte" o proyecto general de sentido de los derechos fundamentales, vale decir es en su más íntima entraña todo un nuevo modo de abrir el sentido de los enunciados constitucionales sobre derechos fundamentales. ${ }^{90}$

$\mathrm{Su}$ influencia ha rebasado las fronteras de Alemania, llegando a otros países como Argentina, Chile, Colombia, Portugal, e incluso a Estados Unidos bajo la figura de la state action. ${ }^{91}$ En España, si bien la Constitución de 1978 no recogió de manera expresa la eficacia horizontal de los derechos fundamentales, el Tribunal Constitucional español la reconoció tempranamente en sus primeras sentencias.

\section{0. $L a$ eficacia horizontal de los derechos y la Constitución Española de 1978}

Es cierto, como acabamos de decir, que la Constitución Española no contiene un artículo en el que se reconozca claramente la eficacia horizontal de los derechos fundamentales, como sí lo hacen la Constitución de Portugal de 1976 en su artículo 18.1 que reza: "los preceptos relativos a los derechos, libertades y garantías son directamente aplicables a las entidades públicas y privadas y vinculan a éstas"; o como la Constitución colombiana de 1991, en cuyo numeral 86 establece la acción de tutela como medio de protección ante la violación de los derechos fundamen-

90 Derechos fundamentales y relaciones entre particulares, op. cit., nota 10, p. 140.

91 Además, su reconocimiento rebasará los derechos reconocidos en las Constituciones nacionales y llegará hasta los derechos humanos reconocidos en tratados internacionales. Véase al respecto Eissen, M. A., "La Convention Européenne des droits de l'homme et les obligations de l'individu: une mise a jour", en Varios Autores, René Cassin amicorum discipulorumque liber, cit., nota 2, t. III, pp. 151 y ss. 
tales cometidas por la autoridad pública o por particulares. Pero también es cierto que no existe en la carta magna española algún enunciado que prohíba la Drittwirkung, por lo que resulta necesario hacer una interpretación armónica de su contenido, a fin de deducir la existencia de argumentos que sustenten la eficacia horizontal de los derechos. Y de hecho, parece haber evidencias más que suficientes para defender que los mencionados derechos son susceptibles de ser aplicados en las relaciones particulares, claro está, en la medida en que esto venga permitido por su propio significado. ${ }^{92}$

En primer lugar, debe invocarse el artículo 1.1. CE, que menciona a "la libertad, la justicia, la igualdad y el pluralismo político" como valores superiores de todo ordenamiento jurídico español, lo que nos hace recordar la dimensión objetiva de los derechos fundamentales. También debemos mencionar al artículo 9.1 de la CE que sujeta tanto a los ciudadanos como a los poderes públicos a la observancia de la Constitución y del resto del ordenamiento. Por su parte, el artículo 9.2 de la CE señala que los derechos no son sólo límites a la autoridad del Estado, sino también mandatos que éste deberá realizar en aras de promover "las condiciones para que la libertad y la igualdad del individuo y de los grupos en que se integra sean reales y efectivas...". Por último, el artículo 10.1 señala que: "la dignidad de la persona, los derechos inviolables que le son inherentes, el libre desarrollo de la personalidad, el respeto a la ley y a los derechos de los demás son fundamento del orden político y de la paz social", lo que implica el reconocimiento de ciertos valores en los que se sustenta el orden jurídico y la vida en sociedad.

Aunado a estos preceptos que establecen el carácter normativo de la Constitución Española, deben mencionarse aquellos que reconocen determinados derechos que por su naturaleza tienen una mayor eficacia en las relaciones particulares, como es el caso de los ya mencionados derechos de la personalidad (honor, intimidad y propia imagen) consagrados en el artículo 18 de la CE; los derecho laborales del artículo 28 de la CE o el mismo derecho de igualdad recogido en el artículo 14 de la CE.

También deben invocarse los artículos que contienen las garantías de protección de los derechos fundamentales, como el artículo 53.1 de la CE que señala: "los derechos y libertades reconocidos en el capítulo segun-

92 Naranjo de la Cruz, R., Los límites de los derechos fundamentales en las relaciones entre particulares... cit., nota 76, p. 199. 
do del presente título vinculan a todos los poderes públicos...”. Si bien es cierto que para algunos autores, este artículo significa la expresión más clara de que los derechos fundamentales se ostentan sólo frente al Estado ${ }^{93}$ y que no pueden por tanto invocarse ilícitamente para romper el marco normativo y contractual de las relaciones jurídico públicas, para otros, como J. Ballarín Iribarren este numeral de la carta española no se refiere en exclusiva a las violaciones de los derechos cometidos por los poderes públicos, como lo hace el artículo 19.4 de la Ley Fundamental de Bonn; por el contrario, dice este autor, lo que no hay es una base textual para afirmar, con carácter general, que los derechos fundamentales se tienen sólo frente a los poderes públicos. ${ }^{94} \mathrm{En}$ el mismo sentido, L. Prieto Sanchís sostiene que la "circunstancia de que en el apartado primero (del artículo 53 de la CE) se diga que los derechos fundamentales vinculan a todos los poderes públicos, omitiendo cualquier referencia a los sujetos privados, no tiene... ningún efecto excluyente en relación con los particulares". ${ }^{95}$

En conclusión, y como ha quedado demostrado, la Constitución de 1978 proporciona argumentos bastantes para aceptar la vigencia de la eficacia horizontal de los derechos fundamentales en el ordenamiento jurídico español.

11. El reconocimiento de la eficacia horizontal de los derechos por el Tribunal Constitucional español

Si de todas formas el análisis del articulado constitucional recién hecho pareciera insuficiente para afirmar la existencia de la Drittwirkung, lo cierto es que la interpretación de la carta magna española — que tanto la generalidad de la doctrina como el mismo Tribunal Constitucional a través de varias sentencias han hecho-, ha sido en el sentido de una constitución normativa y de aplicabilidad directa inserta en un Estado

93 Jiménez Campo, J., op. cit., nota 25, p. 82. En este sentido véanse las SSTC 6/1988, de 21 de enero, FJ 6o.; 5/1981, de 13 de febrero, FJ 9o.; STC 197/1988, de 24 de octubre, FJ 4o.

94 Ballarín Iribarren, J., op. cit., nota 9, pp. 329 y ss.

95 Estudios sobre derechos fundamentales, op. cit., nota 8, p. 211. 
social y democrático de derecho, o al menos que "se propugne por un modelo de Estado abstencionista parece difícil rechazar cualquier tipo de proyección de los derechos en la esfera privada". ${ }^{96}$

De tal forma que, como ya hemos dicho, los derechos fundamentales contenidos en la carta magna española, no son ya principios programáticos sino derechos directamente aplicables y tutelables judicialmente no sólo frente al poder público, sino también frente a otros poderes fácticos, y si se parte de la idea, hoy incuestionable, de unidad del ordenamiento jurídico, es difícil mantener que las relaciones jurídico-privadas sean guetos impermeables a los derechos fundamentales regulados en la Constitución. ${ }^{97}$

\section{El reconocimiento de los derechos fundamentales como valores objetivos del ordenamiento jurídico}

Hay que destacar en primer lugar el reconocimiento que el Tribunal Constitucional hizo desde sus primeras sentencias de la doble dimensión de los derechos fundamentales, subjetiva y objetiva, así como de los deberes positivos del Estado, en el marco de la nueva concepción de éste como social y democrático de derecho en el que se constituía España de acuerdo con la Constitución de 1978. Sentencias que debido a su importancia y claridad consideramos pertinente citar textualmente.

En la STC 25/1981, de 14 de julio, en su FJ 5o., por ejemplo, el máximo tribunal afirmó:

...los derechos fundamentales son derechos subjetivos, derechos de los individuos no sólo como derechos de los ciudadanos en sentido estricto, sino en cuanto garantizan un estatus jurídico o la libertad en un ámbito de la existencia. Pero al propio tiempo, son elementos esenciales de un ordenamiento creativo de la comunidad nacional, en cuanto ésta se configura como marco de una convivencia humana justa y pacífica, plasmada históricamente en el Estado de derecho y, más tarde, en el Estado social de derecho o Estado social y democrático de derecho, según la fórmula de nuestra Constitución (artículo $1.1)$.

96 Venegas Grau, M., op. cit., nota 10, p. 226.

97 Sarazá Jimena, R., “Jueces, derechos fundamentales y relaciones entre particulares”, Jueces para la Democracia, Madrid, núm. 56, julio de 2006, p. 258. 
Años después, en su sentencia 53/1985, de 11 de abril FJ 4o., el Tribunal Constitucional hace algunas referencias al ámbito, significación y función de los derechos fundamentales en el constitucionalismo de nuestro tiempo inspirado en el Estado social de derecho. En este sentido, - dirá la sentencia - la doctrina ha puesto de manifiesto — en coherencia con los contenidos y estructuras de los ordenamientos positivos-que los derechos fundamentales no incluyen solamente derechos subjetivos de defensa de los individuos frente al Estado, y garantías institucionales, sino también deberes positivos por parte de éste (véase al respecto artículos 9.2; 17.4; 18.1 y 4o.; 20.3; 27 de la CE). Además —agrega— los derechos fundamentales son los componentes estructurales básicos, tanto del conjunto del orden jurídico objetivo como de cada una de las ramas que lo integran, en razón de que son expresión jurídica de un sistema de valores que, por decisión del Constituyente, ha de informar el conjunto de la organización jurídica y política; son, en fin, como dice el artículo 10 de la Constitución Española, el "fundamento del orden jurídico y la paz social".

De la significación y finalidades de estos derechos dentro del orden constitucional se desprende que la garantía de su vigencia no puede limitarse a la posibilidad del ejercicio de pretensiones por parte de los individuos, sino que ha de ser asumida también por el Estado. Por consiguiente, de la obligación del sometimiento de todos los poderes a la Constitución no solamente se deduce la obligación negativa del Estado de no lesionar la esfera individual o institucional protegida por los derechos fundamentales, sino también la obligación positiva de contribuir a la efectividad de tales derechos, así como de los valores que representan, aun cuando no exista una pretensión subjetiva por parte del ciudadano. Ello obliga especialmente al legislador, que recibe de los derechos fundamentales "los impulsos y líneas directivas", obligación que adquiere ésta pese a la relevancia allí donde un derecho o valor fundamental quedaría vacío de no establecerse los supuestos para su defensa.

El reconocimiento por parte del Tribunal Constitucional de que la dimensión objetiva de los derechos fundamentales se traduce en un mandato de protección para el Estado, también puede observarse de manera clara en su sentencia 129/1989 de 17 de julio, al decir:

el significado que los derechos adquieren dentro del orden constitucional impone a los poderes públicos el deber de garantizar su efectiva vigencia y, es- 
pecialmente, obliga al legislador a proteger los valores positivados y formalizados en el ordenamiento a través de los derechos fundamentales.

\section{El reconocimiento de la eficacia horizontal de los derechos} fundamentales en las relaciones particulares

No obstante que el Tribunal Constitucional parece acoger sin empacho la dimensión objetiva de los derechos fundamentales y el mandato de protección que deriva de ella, donde se ha mostrado más vacilante, ha sido a la hora de determinar el tipo de eficacia horizontal de los derechos fundamentales en el sistema jurídico español.

En la STC 114/1995, de 6 de julio, queda claro que el Tribunal Constitucional reconoció la eficacia horizontal de los derechos en las relaciones particulares al señalar en su FJ 20.:

ciertamente, el reconocimiento, acertado o no, de un determinado derecho fundamental o de un determinado alcance del mismo por parte de quien tiene competencia para ello puede y de hecho suele tener repercusiones, incluso notables, sobre otros derechos u otros intereses legítimos de otros ciudadanos, o incluso sobre importantes intereses sociales o colectivos (STC 52/87 FJ 3o.; STC 148/94 FJ 4o.). Pues los efectos de los derechos fundamentales, incluso de los derechos de libertad, rara vez circunscriben al estricto ámbito de la composición entre el poder público y el individuo aislado. Por el contrario desde su mismo origen, la noción de los derechos, con su consiguiente pretensión de efectividad, supuso una alteración de las relaciones sociales, y no sólo del simple modo de ejercicio del poder político.

Anteriormente, en su resolución 18/1984, (el leading case en esta materia), el Tribunal Constitucional parece haberse inclinado por un reconocimiento inmediato de la eficacia horizontal de los derechos. En su FJ 6o., dijo:

no debe interpretarse en el sentido de que sólo sea titular de los derechos fundamentales y libertades públicas en relación con los poderes públicos, dado que en un Estado social de derecho como el que consagra el artículo 1o. de la Constitución no puede sostenerse con carácter general que el titular de tales derechos no lo sea en la vida social, tal y como evidencia la Ley 62/1978, de Protección de los Derechos Fundamentales, la cual prevé la vía penal —aplicable cualquiera que sea el autor de la vulneración cuando se cae dentro del 
ámbito penal-, la contencioso administrativa - ampliada por la disposición transitoria 2a., 2, de la LOTC - y la civil no limitada por razón del sujeto autor de la lesión. Lo que sucede, de una parte, es que existen derechos que sólo se tienen frente a los poderes públicos (como los del artículo 24) y, de otra, que la sujeción de los poderes públicos a la Constitución (artículo 9.1) se traduce en un deber positivo de dar efectividad a tales derechos en cuanto a su vigencia en la vida social, deber que afecta al legislador, al Ejecutivo y a los jueces y tribunales, en el ámbito de sus funciones respectivas.

Para L. Prieto Sanchís esta sentencia representa "el reconocimiento más claro de la eficacia horizontal de los derechos" por parte del Tribunal Constitucional; ${ }^{98}$ mientras que para J. M. Bilbao Ubillos, "parece apuntar en la dirección de una eficacia mediata de los derechos fundamentales"; 99 y para J. Alfaro Águila-Real100 esta sentencia "no establece qué nivel de protección en las relaciones entre particulares es imprescindible para garantizar la vigencia de los derechos fundamentales en la vida social", aunque reconoce qué "vigencia han de tener".

Donde el Tribunal Constitucional ha admitido una eficacia horizontal inmediata de los derechos fundamentales es sin duda en los casos laborales, donde se ha reconocido que ciertos derechos como los de libertad sindical, intimidad, libertad de expresión, entre otros, limitan las facultades de dirección y organización del empresario privado. Cuando el Tribunal Constitucional declara, por ejemplo, la nulidad de un despido por violación de un derecho fundamental, reconoce expresamente que ese derecho ha sido vulnerado por el empleador en el marco de la relación laboral, no el derecho del trabajador a que el órgano judicial interprete la legislación laboral con arreglo a los valores constitucionales, ni su derecho a la correcta aplicación del sistema de fuentes. ${ }^{101}$

De cualquier forma, queda claro que el más alto tribunal reconoce que los derechos fundamentales vinculan a los particulares en sus relaciones privadas. Además, debe recordarse, como ya se dijo arriba, que la Drittwirkung no se puede predicar en abstracto ni de manera general respecto

98 Prieto Sanchís, L., op. cit., nota 8, p. 212.

99 Bilbao Ubillos, J. M., op. cit., nota 46, pp. 387 y ss.

100 Alfaro Águila-Real, J., op. cit., nota 1, p. 69.

101 Bilbao Ubillos, J. M., op. cit., nota 46, pp. 322 y 323. Véase el magnífico estudio jurisprudencial que hace este autor a partir de la p. 383. 
de todos los derechos fundamentales, sino que dependerá de la naturaleza de cada uno de ellos.

\section{La eficacia horizontal de los derechos y el poder público}

Pero reconocer que los derechos fundamentales surten efectos en las relaciones particulares no representa ninguna aportación, sino más bien el planteamiento del problema. ${ }^{102}$ Más allá de una discusión doctrinal de si los derechos fundamentales vinculan a los poderes públicos o también a los particulares, y si en este caso lo hacen de manera directa como derechos subjetivos o de forma indirecta como valores del ordenamiento, el problema radica en hacerlos verdaderamente válidos en las relaciones privadas, es decir, en encontrar la solución que evite dichas violaciones, o que las remedie una vez cometidas. Cuestión a la que dedicaremos las siguientes páginas de este trabajo.

El remedio judicial por antonomasia para proteger los derechos fundamentales ha sido el recurso de amparo, por lo que parece lógico acudir a él cuando se está alegando la defensa de estos en las relaciones privadas. Como dice T. Quadra-Salcedo: “...conceder el amparo a quien ha visto vulnerado un derecho fundamental por el poder público y no concederlo, en cambio, a quien ha sufrido esa misma vulneración por parte de un particular encierra una desigualdad que no encuentra fácil explicación". ${ }^{103}$

De tal modo que la pregunta que debe hacerse es si cabe o si debería caber el recurso de amparo contra las violaciones a los derechos fundamentales cometidas por los particulares. ${ }^{104} \mathrm{La}$ respuesta es negativa, pues como recuerdan González Pérez, Cano Mata y Cascajo-Jimeno, "el recurso de amparo está concebido para proteger al ciudadano de las infracciones que, contra tales derechos, pueda cometer el Estado". ${ }^{105}$

102 Como observa Ballarín Iribarren, J., "afirmar que un derecho fundamental limita también a los particulares constituye el comienzo de los problemas interpretativos y constructivos, no la solución del problema”, op. cit., nota 9, p. 292.

103 Quadra-Salcedo, T., El recurso de amparo..., cit., nota 51, p. 13

104 La pregunta que se encuentra por doquier no es la de si los derechos fundamentales rigen en las relaciones entre particulares (cuestión previa a la que, desde una interpretación progresista, no puede sino de forma entusiasta responderse afirmativamente), sino la de si cabe el recurso de amparo por violaciones que tengan su "origen" (esto sí) en ellas. García Torres, J. y Jiménez-Blanco, A., op. cit., nota 9, p. 11.

105 Ibidem, p. 45. 
Los artículos 53.2 y 161.1.b de la CE a diferencia de lo que establece el artículo 93.1.4.a de la Ley Fundamental de Bonn, no especifican que el recurso de amparo se circunscriba únicamente frente a las violaciones de derechos fundamentales cometidas por los poderes públicos, pero el artículo 41.2 de la LOTC ${ }^{106}$ sí señala que el recurso de amparo se restringe a las vulneraciones de los derechos fundamentales que provengan de la actuación de los poderes públicos, cerrándose, en principio, cualquier posibilidad de acceso al recurso de amparo de aquellas violaciones cometidas por los particulares. ${ }^{107}$ A juicio de J. García Torres, y A. JiménezBlanco, "la consideración conjunta de los artículos 53.2 y 161.1 b CE y 41 (1o. y 2o.) y 44.1 LOTC impondría negar acceso al amparo constitucional a la violaciones de los derechos del artículo 53.2 de la C.E. cuando éstas se deban al acto de un particular". ${ }^{108}$

Al respecto, el Tribunal Constitucional ha sido muy tajante al señalar en su Auto 162/1985 de 6 de marzo FJ 1o. que: "sus actos, ${ }^{109}$ al igual que los de cualquier otro particular, efectuados como sujetos de relaciones interprivadas, no son en sí y por sí revisables por este Tribunal”. De igual forma, en el ATC 502/1986 de 11 de junio el Tribunal afirmó que:

El amparo constitucional se da contra los actos de los poderes públicos que lesionen los derechos fundamentales de los ciudadanos. Quiere ello decir que la eventual lesión del derecho al honor que los particulares puedan cometer es tema respecto del cual este Tribunal no tiene por qué pronunciarse.

106 Dice el artículo 41.2 de la LOTC: "el recurso de amparo constitucional protege a todos los ciudadanos, en los términos que la presente Ley establece, frente a las violaciones de los derecho y libertades a que se refiere el apartado anterior, originadas por disposiciones, actos jurídicos o simple vía de hecho de los poderes públicos del Estado, las comunidades autónomas y demás entes públicos de carácter territorial, corporativo o institucional, así como de sus funcionarios o agentes".

107 Bilbao Ubillos, J. M., op. cit., nota 46, p. 135. Para L. Prieto Sanchís la ampliación legal del ámbito objetivo del recurso de amparo contra actos de particulares, no implicaría un desmedido incremento del número de recursos presentado, puesto que, de hecho y por caminos más tortuosos, el Tribunal viene admitiendo este tipo de demandas, op. cit., nota 8 , p. 218.

108 García Torres, J. y Jiménez-Blanco, A., op. cit., nota 29, p. 84.

109 Los de un hospital actuando como un empresario más, sometido a la legislación laboral. 
Tales lesiones dan origen a los diferentes medios de defensa que el ordenamiento jurídico reconoce y que se decidirá ante los tribunales ordinarios. ${ }^{110}$

Debemos aceptar que el recurso de amparo no puede proceder contra las violaciones de derechos fundamentales procedentes de particulares, pues se caería en el absurdo de que toda controversia privada sería residenciable ante el Tribunal Constitucional. Pero no por lo anterior debe concluirse que, al no proceder el recurso de amparo como solución a las transgresiones de los derechos fundamentales cometidas en las relaciones particulares, la eficacia horizontal de los derechos sea inexistente. ${ }^{111}$ Consciente de esta problemática y preocupado de que los derechos fundamentales pudieran quedar sin protección en las relaciones privadas, el Tribunal Constitucional ha recurrido, entre otras alternativas, a la teoría de la asunción judicial.

\section{La teoría de la asunción judicial}

La asunción judicial consiste en imputar la violación de un derecho fundamental que tuvo su origen en una relación privada al Poder Judicial. Todo conflicto entre particulares es residenciable ante los tribunales ordinarios; éstos son parte del poder público y por lo tanto se encuentran vinculados a los derechos fundamentales, no sólo en un sentido negativo de "no hacer", sino también mediante un deber de protección, por lo que si el juez en su actuación no protege debidamente un derecho fundamental, se entiende que lo ha violado, y su resolución, como actuación del

110 Véanse también los AaTC 11/1982, de 10 de mayo; 169/1986, de 19 de febrero; 103/1987, de 28 de enero; 216/1988, de 15 de febrero; 526/1989, de 30 de octubre; 285/1991, de 16 de septiembre, y 348/1992, de 25 de noviembre. En el mismo sentido las SsTC 94/1983, de 14 de noviembre; 101/1989, de 5 de junio, y 112/1989, de 19 de junio.

111 Peces-Barba Martínez G., señala: "una cosa es que los derechos fundamentales existan y se puedan esgrimir en las relaciones particulares, con los límites que el carácter propio del derecho privado supone, y otra diferente que esos derechos puedan tener acceso en caso de violación al recurso de amparo constitucional", op. cit., nota 12, p. 348, de igual forma afirma Naranjo de la Cruz, R., "una cosa es que el significado del derecho permita su extensión a las relaciones entre particulares y otra, que ante dicha vulneración quepa el recurso de amparo", Los límites de los derechos fundamentales en las relaciones entre particulares, cit., nota 76, p. 207. 
Estado, es recurrible en amparo ante el Tribunal Constitucional. ${ }^{112}$ Éste conocerá del recurso y declarará, si así lo considera, la nulidad del acto judicial por haber transgredido el derecho en cuestión, en tanto que no lo protegió, obligando al órgano judicial a reparar dicha violación, ${ }^{113}$ y así en última instancia se reparará la violación del derecho fundamental que se cometió en una relación privada.

La asunción judicial supone la obligación de jueces y tribunales ordinarios de prestar una protección efectiva a los derechos fundamentales frente a violaciones cometidas por sujetos privados. ${ }^{114}$ Como no puede imputarse directamente la actividad de un particular como violación de un derecho fundamental, "el presupuesto necesario para... activar el mecanismo de la asunción judicial es justamente la complicidad de un poder público, su pasividad ante una determinada lesión es la violación que se denuncia". ${ }^{115}$ Se imputa la violación de dicho derecho al órgano judicial

112 Quadra-Salcedo explica la teoría de la asunción judicial en los siguientes términos: "puesto que todo conflicto entre particulares puede acceder libremente a los tribunales ordinarios y éstos son parte de los poderes públicos, del Poder Judicial, las decisiones de los tribunales, si se entiende que no protegen adecuadamente y correctamente los derechos y libertades, pueden ser recurridas ante el Tribunal Constitucional por la vía de amparo, puesto que aquí ya tenemos un acto del poder público que ha desconocido un derecho fundamental. Por este medio podrían acceder al TC todas las violaciones de derechos fundamentales originadas en las relaciones entre particulares y formalizadas procesalmente ante un tribunal", El recurso de amparo y los derechos fundamentales en las relaciones entre particulares, cit., nota 51, pp. 14 y 15; por su parte, J. García Murillo es muy claro cuando dice: "los ciudadanos están sujetos a la Constitución y, por tanto, a los derechos fundamentales, que tienen obligación de respetar; los jueces y tribunales, por su parte, están obligados a respetar los derechos fundamentales, de suerte que el incumplimiento, por parte de los particulares, de su obligación de respetarlos puede dar lugar a una acción sin pretensión de tutela o reparación ante los órganos jurisdiccionales; por último, el eventual incumplimiento por los órganos judiciales de su obligación de amparar el derecho permite acudir al amparo constitucional, La protección judicial de los derechos fundamentales, cit., nota 27, p. 201; J. García Torres y Jiménez-Blanco son todavía más concretos: "todas las controversias sobre derechos de los particulares son residenciables ante el juez; y el juez es, ahora ya sin duda, un poder público que puede violar derechos fundamentales y por tanto se justifica un recurso de amparo ante el Tribunal Constitucional", Derechos fundamentales y relaciones entre particulares, cit., nota 29 , p. 37

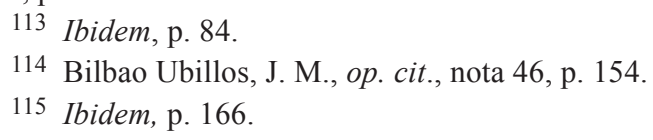


en la medida en que, a juicio del perjudicado, no se reparó la infracción sometida a su conocimiento, ${ }^{116}$ aunque la infracción del derecho fundamental tiene su origen en una conducta privada. ${ }^{117}$

El origen de la asunción judicial se remonta al ya mencionado caso Lüth, en el que el Tribunal de Karlsruhe consideró que el juez ordinario no tomó en cuenta el efecto irradiación de los derechos fundamentales en las relaciones privadas, incurriendo en su vulneración, y al ser la resolución judicial un acto del poder público, éste se pudo impugnar ante el Tribunal Constitucional alemán.

En España, el Tribunal Constitucional ha recurrido a la asunción judicial en numerosas ocasiones, pero el que se considera el caso Lüth español, según J. García Torres, y A. Jiménez-Blanco, ${ }^{118}$ es la ya citada sentencia 18/1984 en la que el máximo Tribunal señaló:

La sujeción de los poderes públicos a la Constitución (artículo 9.1) se traduce en un deber positivo de dar efectividad a tales derechos en cuanto a su vigencia en la vida social, deber que afecta al legislador, al Ejecutivo y a los jueces y tribunales, en el ámbito de sus funciones respectivas. De donde resulta que el recurso de amparo se configura como un remedio subsidiario de protección de los derechos y libertades fundamentales, cuando los poderes públicos han violado tal deber.

Para J. M. Bilbao Ubillos, ${ }^{119}$ en cambio, la sentencia con la que el Tribunal Constitucional ha alcanzado su madurez en este tema es la 55/1983, de 22 de junio, en cuyo FJ 5o. se afirma: "[E]ntiende esta Sala (la Segunda) que, cuando se ha pretendido judicialmente la corrección de los efectos de una lesión de tales derechos y la sentencia no ha entrado

\footnotetext{
116 Ibidem, p. 169.

117 García Torres sostiene que: "Si al órgano judicial le es imputable un déficit de protección del derecho fundamental es porque el derecho fundamental debía ser protegido, lo que es tanto como dar por supuesto que debía ser canon de valoración y pauta de medida en las relaciones entre particulares". "Aunque el déficit de protección del derecho sea imputable al juez, «la lógica obliga a aceptar que la lesión inicial u originaria del derecho se produjo en la relación Inter privatos»", García Torres, J., "Reflexiones sobre la eficacia vinculante de los derechos fundamentales", Poder Judicial, núm. 19, 1988, p. 28.

118 García Torres, J. y Jiménez-Blanco, A., op. cit., nota 29, p. 87.

119 Bilbao Ubillos, J. M., op. cit., nota 46, p. 152.
} 
a conocerla... es la sentencia la que entonces vulnera el derecho fundamental en cuestión".

Otras sentencias en las que el Tribunal Constitucional acude a la asunción judicial son por ejemplo, la 51/1988, de 22 de marzo, FJ 1o., en la que se dice: "por las exigencias técnico procesales referidas el recurso de amparo sólo es viable si en caso de lesión de la libertad sindical por persona o entidad privada, media un acto judicial que no repare las lesiones supuestamente verificadas". De igual forma, la STC 171/1990 de 12 de noviembre FJ 4o., señala:

cuando se ejerce una acción civil para protección del bien jurídico honor o intimidad frente al ejercicio del derecho reconocido en el artículo $20 \mathrm{CE}$ la decisión judicial ha de fundarse necesariamente en una determinada concepción de estos bienes y derechos y de su recíproca relación. Si esta concepción no es la constitucionalmente adecuada, la decisión judicial, como acto del poder público, habrá de reputarse lesiva de uno u otro derecho fundamental, sea por haber considerado ilícito su ejercicio, sea por no haberle otorgado la protección que debería otorgarle.

Y por último, la STC 178/1993 de 31 de mayo FJ 2o., que menciona: "la función del Tribunal en este tipo de recursos consiste en dilucidar si la ponderación judicial de los derechos en presencia ha sido realizada de modo que se respete su correcta valoración y definición constitucional".

La asunción judicial es en realidad el mecanismo procesal utilizado por el Tribunal Constitucional para conocer de recursos de amparo que tienen como objeto una actuación del Poder Judicial, aunque en el fondo, se conoce de la vulneración de un derecho fundamental en una relación jurídico-privada. De esta forma, el Tribunal Constitucional se da la posibilidad de entrar a conocer violaciones de derechos fundamentales en las relaciones particulares, pues

no ha querido privarse del poder de reaccionar contra las que, a su juicio, pudieran ser interpretaciones "erróneas y lesivas" de los órganos del Poder Judicial en materia de derechos fundamentales accionables en amparo, aun cuando la violación del derecho originada directa e inmediatamente por el acto de un particular. ${ }^{120}$

120 García Torres, J. y Jiménez-Blanco, A., op. cit., nota 29, p. 83. 
Si hay algo que queda claro en la jurisprudencia constitucional, según señala J. M. Bilbao Ubillos, es que sólo cuando el Tribunal aprecia la existencia de una determinada violación cometida antes del proceso por un sujeto privado puede imputarse ésta al órgano judicial mediante el expediente técnico de la asunción judicial. Si no se ha producido, a juicio del Tribunal, una vulneración extrajudicial de alguno de los derechos fundamentales del recurrente, no se pone en marcha el mecanismo que permite la transformación de esa vulneración imputable a la resolución judicial. ${ }^{121}$

Al resolver los casos de amparo, el Tribunal Constitucional está conociendo

la licitud constitucional de la conducta privada presuntamente lesiva de un derecho fundamental. Con su decisión, el Tribunal resuelve precisamente la controversia que venían protagonizando personas o entidades privadas. Enjuicia los hechos relacionados con ese conflicto y después de sopesar las razones de las dos partes implicadas, se pronuncia acerca de la violación que se denuncia. ${ }^{122}$

\section{Los problemas de la asunción judicial}

La teoría de la asunción judicial ha sido una alternativa de solución que ha resultado adecuada para remediar las violaciones de derechos fundamentales cometidas por particulares y en términos generales, bien acogida por la doctrina. J. GArcía Torres y A. Jiménez Blanco dicen que se trata de un "hallazgo inapreciable porque concilia el velo de toda apariencia de Drittwirkung con el tácito acogimiento de las más vigorosa Drittwirkung latente", ${ }^{123}$ y J. M. Bilbao Ubillos la califica como una "ficción útil" 124 y con "una importante función pedagógica". ${ }^{125}$ No obstante, no queda exenta de críticas y problemas de configuración.

121 La eficacia de los derechos fundamentales frente a particulares..., cit., nota 46, p. 211; en el mismo sentido Prieto Sanchís, L., op. cit., nota 8, p. 213.

122 Ibidem, p. 85.

123 García Torres, J. y Jiménez-Blanco, A., op. cit., nota 29, p. 140.

124 Bilbao Ubillos, J. M., op. cit., nota 46, p. 223.

125 Ibidem, p. 228. 


\section{Las limitaciones del artículo 44 de la LOTC}

Debe señalarse que la asunción judicial es más complicada de lo que hasta el momento parece, pues para que el recurso de amparo proceda contra actuaciones del Poder Judicial, deben satisfacerse ciertos requisitos que establece el artículo 44.1 de la LOTC.

El primero de ellos consiste en agotar previamente todos los medios de impugnación previstos por las normas procesales; y el segundo y más importante, en "que la violación del derecho o libertad sea imputable de modo inmediato y directo a una acción u omisión del órgano judicial con independencia de los hechos que dieron lugar al proceso en que aquéllas se produjeron...". La intención de este artículo es, o mejor dicho era, evitar precisamente la entrada del recurso de amparo por violaciones a derechos fundamentales cometidas por particulares. ${ }^{126}$ Sin embargo, en una interpretación flexible de este artículo 44.1 inciso inicial, apartado b), de la LOTC, el Tribunal Constitucional ha atribuido la vulneración constitucional del derecho a la omisión de jueces y tribunales consistente en no corregir debidamente, restableciendo los derechos conculcados, la vulneración imputable originariamente a simples particulares, si bien, para que ello sea posible será necesario, al menos, que el lesionado haya alegado directamente ante el tribunal o juez correspondiente la vulneración, dando así la posibilidad de que pueda repararse la lesión. ${ }^{127}$

Quadra-Salcedo considera que este requisito significa que la resolución judicial "debe haber tenido por objeto directo un derecho fundamental", 128 mientras que para J. M. Bilbao Ubillos puede hablarse de "imputación al órgano judicial tanto en el supuesto en el que el Tribunal no haya interpretado conforme a la Constitución, como en el supuesto en el que no haya reparado una lesión causada previamente por un particular". Para imputarle la violación al órgano judicial dice J. M. Bilbao Ubillos "tiene que producirse una ratificación judicial de la violación inicial, una co-

126 Véase al respecto Rubio Llorente, F., "Sobre la relación entre el Tribunal Constitucional y el Poder Judicial en el ejercicio de la jurisdicción constitucional", REDC, año 2 , núm. 4, 1982, p. 66.

127 Véanse, entre otras, la STC 9/1981, del 31 de marzo, y el ATC 1074/1988, del 26 de septiembre.

128 Quadra-Salcedo, T., El recurso de amparo y los derechos fundamentales en las relaciones entre particulares, cit., nota 51, pp. 96-99. 
nexión, por tanto entre ambas violaciones, la extraprocesal y la cometida con posterioridad por el órgano judicial". ${ }^{129}$

Igualmente, en el FJ 1o. de la Sentencia 231/1988, el Tribunal Constitucional admitió que una sentencia del Tribunal Supremo que restablece y mantiene los efectos de una situación que la recurrente estima atentatoria a sus derechos, puede justificar la interposición de un recurso de amparo. Y por ello, y en cuanto los jueces y tribunales ordinarios están obligados por el artículo 53.2 de la CE a la tutela de los derechos y libertades de los artículos 14 a 29, así como del 30 de la Constitución, procede considerar que la sentencia atacada en amparo ha dado lugar, de forma "inmediata y directa", como exige el artículo 44 de la LOTC, a la citación que la recurrente mantiene, misma que vulnera sus derechos fundamentales", lo cual permite al Tribunal Constitucional concluir que "lo que procede examinar, como objeto del presente amparo, es si la sentencia mencionada efectivamente atenta a los derechos fundamentales que se alegan". ${ }^{130}$

El mismo Tribunal Constitucional ha aludido expresamente al "origen extrajudicial” en su sentencia 171/1989 FJ 2o., así como en la 137/1991, de 20 de junio, FJ 10.: "de existir vulneración del artículo 28.1 de la Constitución, la misma habrá de imputarse a las resoluciones judiciales impugnadas, por no reparar, en su caso, una lesión previa de origen extrajudicial".

Para J. García Torres y A. Jiménez Blanco, la resolución judicial no origina la violación del derecho, simplemente no la remedia, ${ }^{131}$ lo cual es cierto, sin embargo, y como recuerda J. Ballarín Iribarren, la falta de protección judicial frente a una lesión originariamente producida por un particular puede considerarse, a su vez, fuente directa e inmediata de una lesión a ese mismo derecho. ${ }^{132}$

a. La ilusión de la asunción judicial

Se dice además que la asunción judicial es ilusoria en tanto que la conducta que se está recurriendo a través del amparo es la acción cometi-

129 Bilbao Ubillos, J. M., op. cit., nota 46, p. 179.

130 Venegas Grau, M., op. cit., nota 10, p. 173.

131 García Torres, J. y Jiménez Blanco, A., op. cit., nota 29, p. 78.

132 Ballarín Iribarren, J., op. cit., nota 9, p. 305. 
da por el Poder Judicial y no la del particular que transgredió el derecho, así que, tácitamente se está aceptando que el único capaz de transgredir derechos fundamentales es el Estado. ${ }^{133}$

Por el contrario, aunque el Tribunal Constitucional enjuicia la actuación del órgano judicial, lo que conoce en el fondo es la existencia de una violación por parte de un particular (una violación extrajudicial). ${ }^{134}$ Y como ya señalamos antes, el hecho que el recurso de amparo no proceda como medio de solución para remediar las violaciones de derechos fundamentales en las relaciones privadas y que por ello se tenga que acudir a la asunción judicial como alternativa de solución, no implica que se esté desconociendo la eficacia horizontal de los derechos, más bien, con la asunción judicial se ha logrado proteger a los derechos fundamental en las relaciones privadas.

$b$. La reducción de la violación entre particulares a la imputación judicial por falta de protección

Otro problema que plantea la teoría de la asunción judicial es que toda violación de derechos fundamentales en las relaciones privadas se reduce a una falta de protección del juez ordinario. En rigor, lo que controla el Tribunal Constitucional, dice M. Medina, es "la violación del deber de protección de los derechos fundamentales por parte de los órganos judiciales". ${ }^{135}$ Lo cual también es cierto, pero ello no implica negar la existencia de la Drittwirkung, más bien debe reconocerse el esfuerzo por tratar de proteger a los derechos fundamentales en las relaciones particulares sin transgredir el sistema de garantías.

Y si bien es la actuación del órgano judicial la que formalmente se enjuicia, ${ }^{136}$ en el fondo se analiza una actividad inter-privatos, como ejemplifica el ATC 382/1996 de 18 de diciembre FJ 3o.:

133 Así lo afirman J. García Torres y A. Jiménez Blanco cuando dicen que: "curiosamente, ocurre que la doctrina de la Sentencia 78/1982 y de las que han seguido (a saber: no es objeto de amparo la violación producida por un acto de un particular, sino por un acto jurisdiccional) sería perfectamente compatible con la negación (verbalista) de la Drittwirkung", op. cit., nota 29, p. 86.

134 Bilbao Ubillos, J. M., op. cit., nota 46, pp. 209-211.

135 Medina, M., La vinculación negativa del legislador a los derechos fundamentales, McGraw-Hill, 1996, pp. 107 y 108.

136 Bilbao Ubillos, J. M., op. cit., nota 46, p. 209. 
constitucionalmente se subraya su relevancia desde el momento en que el artículo 53.2 de la Constitución Española explícita el deber específico de tutela de los derechos fundamentales que incumbe a los jueces y tribunales ordinarios. Consiguientemente, respecto de las relaciones entre particulares, de los efectos del amparo constitucional, únicamente podrá estimarse vulnerado el derecho fundamental en divisa cuando se constate que los órganos judiciales han incumplido o satisfecha indebidamente el tan reiterado deber de protección. Sólo así, en verdad, resulta en estos supuestos transitable esa vía del amparo constitucional toda vez que la Ley Orgánica de este Tribunal exige que la lesión del derecho tengan su origen inmediato y directo en un acto u omisión de un órgano judicial (artículo 44.1). En definitiva, lo que se recurre en amparo y, en consecuencia, lo que debe ser objeto de control no es genuinamente, sino la falta de tutela de los derechos fundamentales por parte de los resoluciones judiciales impugnadas (por todas SSTC 47/1985, FJ 5o.; 88/1985 GJ 4o.; 6/1988, FJ 1o. Y 231/1988 FJ 1o.).

El mismo Auto dice más adelante:

no se trata, por consiguiente, en esta sede, de revisar cualesquiera errores en que los órganos judiciales pueden incurrir al aplicar la legalidad ordinaria, dado que el amparo constitucional lo que se configura como una última instancia ni cumple una función casacional, sino, más propiamente, de enjuiciar si, al acometer dicha tarea, han valorado convenientemente el alcance y la eficacia de los derechos involucrados en el caso. Pues, de acuerdo con la recién aludida interacción, cuando se procede a la interpretación de cualquier ámbito del derecho, ha de partirse del entendimiento de que más allá del tenor literal de las normas que lo integran el mismo se haya materialmente conformado por los derechos fundamentales.

En otro párrafo, sigue diciendo este Auto:

a los jueces y tribunales ordinarios corresponde, sin embargo, en línea de principio, un cierto margen de apreciación, a este respecto (SSTC 120/1983, FJ 3 y 4; y 41/1984, FJ 2o.), puesto que, como es palmario, el deber de protección dimanante del contenido objetivo de los derechos fundamentales no presentó los perfiles tan nítidos como para entender que el mismo únicamente pueda ser satisfecho, en cada caso, por una sola fórmula correcta de resolución de las específicas controversias. 


\section{c. La asunción judicial y la mittelbare Drittwirkung}

Parece advertirse por lo demás, que la teoría de la asunción judicial va de la mano, o más bien se desprende, de la eficacia horizontal mediata de los derechos fundamentales. M. Aragón Reyes ha dicho que la asunción judicial es una suerte de eficacia indirecta a algunos derechos fundamentales. ${ }^{137}$

Resulta lógico que se asocie la asunción judicial con la mittelbare Drittwirkung, pues ésta se desprende de la dimensión objetiva de los derechos fundamentales, y de ésta también el deber de protección del Estado, en concreto del Poder Judicial. No obstante, son dos cuestiones, una teórica y otra procesal, que deben diferenciarse claramente.

Al analizar con detenimiento el ya varias veces citado caso Lüth, se observan estas dos perspectivas: una sustancial o de fondo, en la medida en que el Tribunal Federal Constitucional alemán adoptó la teoría de la mittelbare Drittwirkung para reconocer de alguna forma la eficacia horizontal de los derechos fundamentales, y otra adjetiva o procesal, en la que el Tribunal Constitucional recurrió a la teoría de la asunción judicial como el instrumento procesal a través del cual se entra a conocer la violación de un derecho fundamental que tuvo su origen en una relación particular. El adjetivo de "finta alemana" que ha recibido esta sentencia se refiere a este último aspecto.

Para no confundir la mittelbare Drittwirkung, con el deber de protección, y consecuentemente con la asunción judicial, deben diferenciarse estos tres momentos: a) que el juez tenga un deber de proteger los derechos fundamentales en las relaciones privadas, misma que se deriva de la concepción del Estado como social y democrático de derecho y en consecuencia de la naturaleza normativa de su Constitución; b) que el juez ordinario deba interpretar los derechos fundamentales como valores en las controversias particulares (mittelbare Drittwirkung); y c) que debido a la falta de protección del derecho por parte del juez, se recurra en amparo ante el Tribunal Constitucional (asunción judicial).

137 Aragón Reyes, M., "Comentario al artículo 161 de la Constitución Española", en Varios Autores, Comentarios a la Constitución Española de 1978, Madrid, Edersa, 1997, t. XII, p. 193. 
Recurrir a la imputación judicial, como el medio de solución procesal para dar validez a los derechos fundamentales en las relaciones particulares, no significa aceptar la eficacia horizontal mediata de éstos.

La distinción no resulta ociosa, pues el mandato de protección de los derechos fundamentales por parte del Estado en las relaciones privadas, también existe aunque se les considere derechos subjetivos (unmittelbare Drittwirkung) y no valores objetivos. J. M. Bilbao Ubillos y J. Ballarín Iribarren parten del reconocimiento de que la relación jurídica de fondo, en que se plantea el conflicto, está regida por un derecho fundamental, por un derecho subjetivo y no por los valores que encarnan concretamente ese derecho. ${ }^{138}$ De la misma idea es M. Venegas Grau al afirmar que: "lo que no logra ocultar la asunción judicial es que lo que está en juego es la eficacia — directa— los derechos fundamentales entre particulares". 139

El Tribunal Constitucional ha reconocido en varias ocasiones, que precisamente, "lo que se dilucida realmente en el proceso constitucional de amparo es la licitud o ilicitud constitucional de la actuación del particular que aparece como presunto autor de la violación inicial". ${ }^{140} \mathrm{Y}$ en sus sentencias, 47/1985 y 88/1985 el más alto tribunal español no sólo anuló las sentencias de las magistraturas y las del Tribunal Superior (Central de Trabajo en un caso; Sala Sexta del Supremo, en el otro), sino que además declaró radicalmente nulo un acto jurídico privado (el despido) e impuso al empleador el deber de readmitir al trabajador.

\section{Jurisdicción ordinaria y jurisdicción constitucional}

Que se reconozca la vigencia de los derechos fundamentales en las relaciones particulares y la asunción judicial como alternativa de solu-

\footnotetext{
138 Ibidem, p. 219.

139 Venegas Grau, M., op. cit., nota 11, p. 196; Bilbao Ubillos, J. M. sostiene que: “...la utilización de este mecanismo procesal — la asunción judicial — no implica la negación de la eficacia frente a terceros de los derechos fundamentales. Muy al contrario, supone, en la práctica, el reconocimiento, en unos casos de su eficacia inmediata y, en otros, de una eficacia mediata, pero por obra no del juez sino del legislador (interpósito legislatoris)", La eficacia de los derechos fundamentales frente a particulares..., cit., nota 46, p. 218.

140 STC 177/1988 de 10 de octubre FJ 1o. y 3o. En el mismo sentido véase la STC 95/1985, de 29 de julio.
} 
ción, no quiere decir que ésta sea la única vía para proteger los derechos fundamentales.

El Tribunal Constitucional ha permitido el acceso al recurso de amparo de las vulneraciones de derechos fundamentales producidos por la actuación de particulares a través de varios mecanismos, como la ampliación del concepto de "poderes públicos" contenido en el artículo 41.2 de la LOTC; o la consideración "dual" del valor de la sentencia judicial en la relación del acto público que debe ser impugnado, según que el origen de la vulneración en la que el derecho fundamental se ubique en una relación jurídica pública o privada. ${ }^{141}$

No obstante, el amparo contra las actuaciones del Poder Judicial no debe convertirse en el único e infalible remedio contra las violaciones de los derechos fundamentales en las relaciones particulares, ni el Tribunal Constitucional puede ser el guardián de todas las conductas privadas. ${ }^{142}$

Parece que tanto referirnos al recurso de amparo y a la asunción judicial, nos hiciera olvidar a la jurisdicción ordinaria como alternativa de solución para remediar las violaciones a derechos fundamentales cometidas en las relaciones privadas y, a decir verdad, ésta es o debe ser la vía principal de protección de los derechos fundamentales en las relaciones particulares. El juez ordinario es el juez de los derechos fundamentales, el garante común, natural de los derechos fundamentales. ${ }^{143}$

Debido a la naturaleza normativa de la Constitución, el juez ordinario tiene un mandato constitucional de proteger los derechos fundamenta-

141 Si la violación del derecho fundamental tiene su origen en un acto del poder público, la sentencia judicial actúa sólo a efectos procedimentales, como agotamiento de la vía judicial previa, pero si la vulneración del derecho fundamental se produce originariamente como consecuencia del acto de un particular, la sentencia judicial actúa a efectos sustantivos, constituyéndose en el acto del poder público que el artículo 41.2 de la Ley Orgánica del Tribunal Constitucional exige que exista para que pueda ser objeto del recurso de amparo. Véase Sarazá Jimena. R., Jueces, derechos fundamentales y relaciones entre particulares, cit., nota 97, p. 579.

142 Quadra-Salcedo, dice que la función del Tribunal Constitucional "no puede ser nunca la de dar soluciones a casos individuales y concretos...", El recurso de amparo y los derechos fundamentales..., cit., nota 51, p. 20.

143 López Guerra, L., "Jurisdicción ordinaria y jurisdicción constitucional”, en Ruiz Rico Ruiz, G. (dir.), La aplicación jurisdiccional de la Constitución, Valencia, Tirant lo Blanch, 1997, p. 32. 
les ${ }^{144}$ que en presencia de una ley se concretizará al aplicar la normativa civil, mercantil o social, siguiendo las normas sobre competencia, legitimación, representación procesal, dirección técnica y tramitación propias de estos procesos, ${ }^{145}$ en caso de no existir normativa alguna, debido a este mismo mandato constitucional, el juez deberá resolver cada caso ponderando los derechos en colisión.

Ya sea en presencia de ley, o en ausencia de ella, si la protección concedida por el juez ordinario a determinado derecho fundamental en un caso concreto, no fue suficiente, la sentencia será recurrible en amparo ante el Tribunal Constitucional, que conocerá del caso y determinará si concede o no la protección pedida anulando la sentencia del juez ordinario. ${ }^{146}$

El Tribunal Constitucional no es el único competente para apreciar la eficacia de los derechos fundamentales en las relaciones jurídico-privadas, como estima P. Pérez Tremps. ${ }^{147}$ Más bien, su función es subsidiaria y extraordinaria de la jurisdicción ordinaria. Conocerá de los recursos de amparo cuando el juez ordinario no haya otorgado la protección estimada a un determinado derecho fundamental pudiendo y debiendo hacerlo. La STC 18/1984 a la que tanto hemos recurrido, ya lo decía: "el recurso de amparo se configura como un remedio subsidiario de protección de los

144 El sistema español no oculta que la responsabilidad de protección de los derechos fundamentales recae sobre todo en los jueces ordinarios, García Morillo, J., op. cit., nota 27, p. 46

145 Sarazá Jimena, R., Jueces, derechos fundamentales y relaciones entre particulares, cit., nota 97, p. 420.

146 Ibidem, p. 862.

147 En nuestra opinión — dicen J. García Torres y A. Jiménez Blanco- "P. Pérez Tremps está motivado por el postulado de preservar coute quie coute la supremacía del Tribunal Constitucional frente al Poder Judicial en materia de derechos accionables en amparo (los demás derechos fundamentales parecen importar menos) y todas las habilidades para sortear los límites constitucionales y legislativos (en especial, los de los artículos 41.2 y 44.1 b) LOTC, cuyo fundamento constitucional es el artículo 161.1 b) CE) le parecen justificadas. A nuestro entender la premisa correcta es la opuesta. El Tribunal Constitucional, en materia de jurisdicción de amparo, tiene las potestades tasadas que resultan de la Constitución y de su ley orgánica, las cuales, según intentamos demostrar en el texto, no alcanzan a entender y fallar casos de Drittwirkung, deba ésta reconocerse o no (lo que equivale a decir que reconocer o no Drittwirkung es decisión que resulta entregada a jueces y tribunales del Poder judicial y no al Tribunal Constitucional y que deberá decidirse en amparo judicial y no en el constitucional)", Derechos fundamentales y relaciones entre particulares..., cit., nota 29, p. 85 . 
derechos y libertades fundamentales cuando los poderes públicos han violado ese deber".

Ahora, si en esta labor subsidiaria el Tribunal Constitucional niega la vigencia de un derecho fundamental en una relación privada determinada, es porque en ese caso concreto el derecho fundamental no tuvo la eficacia que el recurrente pretendía, mas no se está negando la eficacia horizontal de los derechos fundamentales en general. ${ }^{148}$

Tampoco consideramos coherente excluir del todo al Tribunal Constitucional de esta labor, dejando la jurisdicción ordinaria como última y definitiva instancia en esta materia en la que tan directamente se halla concernida la eficacia normativa de la Constitución, porque el papel que la propia Constitución atribuye al Tribunal Constitucional como órgano jurisdiccional superior en materia de garantías constitucionales es difícilmente compatible con la exclusión "en bloque" de una determinada materia relativa a tales garantías constitucionales (como sería la de su vigencia en las relaciones entre particulares) del conocimiento del Tribunal Constitucional a través del recurso de amparo. ${ }^{149}$

La protección de los derechos fundamentales es, entonces, una función jurisdiccional compartida de los tribunales ordinarios y del Tribunal Constitucional. Ambos conocen de casos concretos, en los que han de decidir, a la vista de las particularidades concurrentes, si se ha vulnerado o no un derecho fundamental, y de ser así, actuar en pro de su protección.

148 Sarazá Jimena, R., Jueces, derechos fundamentales y relaciones entre particulares..., cit., nota 97, p. 295.

149 Ibidem, p. 875.

Fecha de recepción: 8 de noviembre de 2009.

Fecha de dictamen: 1o. de diciembre de 2009. 